\title{
Cochrane
}

Library

Cochrane Database of Systematic Reviews

\section{Lay-led and peer support interventions for adolescents with asthma} (Review)

Kew KM, Carr R, Crossingham I

Kew KM, Carr R, Crossingham I.

Lay-led and peer support interventions for adolescents with asthma.

Cochrane Database of Systematic Reviews 2017, Issue 4. Art. No.: CD012331.

DOI: 10.1002/14651858.CD012331.pub2.

www.cochranelibrary.com 
TABLE OF CONTENTS

HEADER 1

ABSTRACT

PLAIN LANGUAGE SUMMARY

SUMMARY OF FINDINGS

BACKGROUND

OBJECTIVES

METHODS

RESULTS

Figure 1.

Figure 2.

DISCUSSION

AUTHORS' CONCLUSIONS

ACKNOWLEDGEMENTS

REFERENCES

CHARACTERISTICS OF STUDIES

DATA AND ANALYSES

Analysis 1.1. Comparison 1 Peer-led vs control, Outcome 1 Change in asthma-related quality of life (PAQLQ).

Analysis 1.2. Comparison 1 Peer-led vs control, Outcome 2 Asthma-related quality of life (MCID).

Analysis 1.3. Comparison 1 Peer-led vs control, Outcome 3 Asthma control.

Analysis 1.4. Comparison 1 Peer-led vs control, Outcome 4 Smoking.

ADDITIONAL TABLES

APPENDICES

CONTRIBUTIONS OF AUTHORS

DECLARATIONS OF INTEREST

SOURCES OF SUPPORT

DIFFERENCES BETWEEN PROTOCOL AND REVIEW

INDEX TERMS 
[Intervention Review]

\section{Lay-led and peer support interventions for adolescents with asthma}

Kayleigh M Kew ${ }^{1,2}$, Robin Carr ${ }^{3}$, lain Crossingham ${ }^{4}$

1British Medical Journal Technology Assessment Group (BMJ-TAG), BMJ Knowledge Centre, London, UK. ${ }^{2}$ Cochrane Airways, Population Health Research Institute, St George's, University of London, London, UK. 328 Beaumont Street Medical Practice, Oxford, UK. ${ }^{4}$ East Lancashire Hospitals NHS Trust, Blackburn, UK

Contact address: Kayleigh M Kew, British Medical Journal Technology Assessment Group (BMJ-TAG), BMJ Knowledge Centre, BMA House, Tavistock Square, London, WC1H 9JR, UK. kkew@sgul.ac.uk.

Editorial group: Cochrane Airways Group.

Publication status and date: New, published in Issue 4, 2017.

Citation: Kew KM, Carr R, Crossingham I. Lay-led and peer support interventions for adolescents with asthma. Cochrane Database of Systematic Reviews 2017, Issue 4. Art. No.: CD012331. DOI: 10.1002/14651858.CD012331.pub2.

Copyright ( 2017 The Cochrane Collaboration. Published by John Wiley \& Sons, Ltd.

\section{A B S T R A C T}

\section{Background}

Adolescents with asthma are at high risk of poor adherence with treatment. This may be compounded by activities that worsen asthma, in particular smoking. Additional support above and beyond routine care has the potential to encourage good self-management. We wanted to find out whether sessions led by their peers or by lay leaders help to reduce these risks and improve asthma outcomes among adolescents.

\section{Objectives}

To assess the safety and efficacy of lay-led and peer support interventions for adolescents with asthma.

\section{Search methods}

We identified trials from the Cochrane Airways Trials Register, which contains reports of randomised trials obtained from multiple electronic and handsearched sources, and we searched trial registries and reference lists of primary studies. We conducted the most recent searches on 25 November 2016.

\section{Selection criteria}

Eligible studies randomised adolescents with asthma to an intervention led by lay people or peers or to a control. We included parallel randomised controlled trials with individual or cluster designs. We included studies reported as full text, those published as abstract only and unpublished data.

\section{Data collection and analysis}

Two review authors screened the searches, extracted numerical data and study characteristics and assessed each included study for risk of bias. Primary outcomes were asthma-related quality of life and exacerbations requiring at least a course of oral steroids. We graded the analyses and presented evidence in a 'Summary of findings' table.

We analysed dichotomous data as odds ratios, and continuous data as mean differences (MD) or standardised mean differences, all with a random-effects model. We assessed clinical, methodological and statistical heterogeneity when performing meta-analyses, and we described skewed data narratively.

\section{Main results}

Five studies including a total of 1146 participants met the inclusion criteria for this review. As ever with systematic reviews of complex interventions, studies varied by design (cluster and individually randomised), duration (2.5 to 9 months), setting (school, day camp, primary 
care) and intervention content. Most risk of bias concerns were related to blinding and incomplete reporting, which limited the metaanalyses that could be performed. Studies generally controlled well for selection and attrition biases.

All participants were between 11 and 17 years of age. Asthma diagnosis and severity varied, as did smoking prevalence. Three studies used the Triple A programme; one of these studies tested the addition of a smoke-free pledge; another delivered peer support group sessions and mp3 messaging to encourage adherence; and the third compared a peer-led asthma day camp with an equivalent camp led by healthcare practitioners.

We had low confidence in all findings owing to risk of bias, inconsistency and imprecision. Results from an analysis of asthma-related quality of life based on the prespecified random-effects model were imprecise and showed no differences (MD 0.40, 95\% confidence interval ( $\mathrm{Cl})-0.02$ to 0.81 ); a sensitivity analysis based on a fixed-effect model and a responder analysis suggested small benefit may be derived for this outcome. Most other results were summarised narratively and did not show an important benefit of the intervention; studies provided no analysable data on asthma exacerbations or unscheduled visits (data were skewed), and one study measuring adherence reported a drop in both groups. Effects on asthma control favoured the intervention but findings were not statistically significant. Results from two studies with high levels of baseline smoking showed some promise for self-efficacy to stop smoking, but overall nicotine dependence and smoking-related knowledge were not significantly better in the intervention group. Investigators did not report adverse events.

\section{Authors' conclusions}

Although weak evidence suggests that lay-led and peer support interventions could lead to a small improvement in asthma-related quality of life for adolescents, benefits for asthma control, exacerbations and medication adherence remain unproven. Current evidence is insufficient to reveal whether routine use of lay-led or peer support programmes is beneficial for adolescents receiving asthma care.

Ongoing and future research may help to identify target populations for lay-led and peer support interventions, along with attributes that constitute a successful programme.

\section{PLAIN LANGUAGE SUMMARY}

\section{Support from peers or lay leaders for adolescents with asthma}

\section{Background to the question}

Adolescents may need extra support to manage their asthma, as they are at higher risk of not taking their inhalers properly and of engaging in activities that may make their asthma worse (such as smoking). We wanted to find out whether sessions led by peers or by lay leaders (i.e. not healthcare professionals) help to reduce these risks and lead to better asthma control. We included studies that compared this support against usual care or a different type of help. We conducted the most recent searches on 25 November 2016.

\section{Study characteristics}

We found five studies including 1146 adolescents with asthma. Studies varied by design, duration (2.5 to 9 months), setting (school, day camp, primary care) and the way that peer support or lay-led sessions were given. Asthma severity varied, as did the number who smoked. Three studies used a programme called Triple A (Adolescent Asthma Action), by which older adolescents are trained to deliver sessions to younger students; one of these studies tested the addition of a pledge to stop smoking; another delivered peer support group sessions including messages played through an mp3 player to encourage adherence; and the third compared an asthma day camp led by peers against one led by nurses and doctors.

\section{Key results}

Adolescents who received peer support had better quality of life than those in the control group, although this varied with how results were analysed, so we were uncertain. Most other outcomes did not show an important benefit of the intervention. These studies provided very little information about asthma attacks or unscheduled visits during the trial, and we couldn't be sure whether the intervention was beneficial in terms of asthma control. Results from two studies in which a lot of the adolescents smoked showed some promise that adolescents had the confidence to stop, but overall nicotine dependence and smoking-related knowledge were not much better than in controls. Studies provided no reports of adverse events.

\section{Quality of the evidence}

We can't be sure of the results because most outcomes were rated by people who knew the group to which adolescents were assigned, and this can affect how people behave and respond to questions. Some studies didn't report everything they said they would, or reported information that we could not analyse. Sometimes study results didn't agree with results of other studies, and often we could not say for certain whether adolescents received benefit. For these reasons, we have low confidence in all study findings. 


\begin{tabular}{|c|c|c|c|c|c|}
\hline \multicolumn{6}{|c|}{$\begin{array}{l}\text { S U M M A R Y O F F I N D I N G S } \\
\text { Summary of findings for the main comparison. }\end{array}$} \\
\hline \multicolumn{6}{|c|}{ Lay-led and peer support interventions compared with usual care for adolescents with asthma } \\
\hline \multicolumn{6}{|c|}{$\begin{array}{l}\text { Patient or population: adolescents with asthma } \\
\text { Settings: school, day camp or primary care } \\
\text { Intervention: lay-led and peer support interventions } \\
\text { Comparison: usual care/no intervention }\end{array}$} \\
\hline \multirow[t]{3}{*}{ Outcomes } & \multicolumn{2}{|c|}{ Illustrative comparative risks ${ }^{\star}(95 \% \mathrm{Cl})$} & \multirow{3}{*}{$\begin{array}{l}\text { Number of partici- } \\
\text { pants } \\
\text { (studies) }\end{array}$} & \multirow{3}{*}{$\begin{array}{l}\text { Quality of the evi- } \\
\text { dence } \\
\text { (GRADE) }\end{array}$} & \multirow[t]{3}{*}{ Comments } \\
\hline & Assumed risk & Corresponding risk & & & \\
\hline & Usual care/no intervention & Lay-led or peer support intervention & & & \\
\hline $\begin{array}{l}\text { Asthma-relat- } \\
\text { ed quality of life } \\
\text { (PAQLQ) } \\
1 \text { to } 7 \text { scale; higher = } \\
\text { better } \\
3 \text { to } 9 \text { months }\end{array}$ & $\begin{array}{l}\text { Mean change in control groups } \\
\text { was } 0.05\end{array}$ & $\begin{array}{l}\text { Mean change in intervention groups was } \\
\mathbf{0 . 4 0} \text { better ( } 0.02 \text { worse to } 0.81 \text { better) }\end{array}$ & $\begin{array}{l}578 \\
\text { (3 RCTs) }\end{array}$ & $\begin{array}{l}\oplus \oplus \Theta \Theta \\
\mathbf{L O W} a, b\end{array}$ & \\
\hline $\begin{array}{l}\text { Asthma-relat- } \\
\text { ed quality of life } \\
\text { (MCID) } \\
8 \text { months }\end{array}$ & 123 per 1000 & $\begin{array}{l}\mathbf{2 4 8} \text { per } 1000 \\
(145 \text { to } 390)\end{array}$ & $\begin{array}{l}251 \\
(1 \mathrm{RCT})\end{array}$ & $\begin{array}{l}\oplus \oplus \ominus \ominus \\
\mathbf{L O W} \text { a,c,d }\end{array}$ & \\
\hline $\begin{array}{l}\text { Asthma control } \\
\text { Scale (range, score) } \\
\text { ACT (5-23) and ACQ } \\
\text { (4-16) } \\
4 \text { to } 9 \text { months }\end{array}$ & \multicolumn{2}{|c|}{$\begin{array}{l}\text { Not pooled. Two studies reported } 2 \text { different measures. Both effects favoured } \\
\text { peer support, but neither result was statistically significant }\end{array}$} & $\begin{array}{l}166 \\
\text { (2 RCTs) }\end{array}$ & $\begin{array}{l}\oplus \oplus \ominus \ominus \\
\text { LOW a,e }\end{array}$ & \\
\hline $\begin{array}{l}\text { Unscheduled visits } \\
9 \text { months }\end{array}$ & \multicolumn{2}{|c|}{$\begin{array}{l}\text { Somewhat fewer mean visits per person in the intervention group than in the } \\
\text { control group, but the data are skewed and are difficult to interpret }\end{array}$} & $\begin{array}{l}84 \\
(1 \mathrm{RCT})\end{array}$ & Not graded & \\
\hline
\end{tabular}




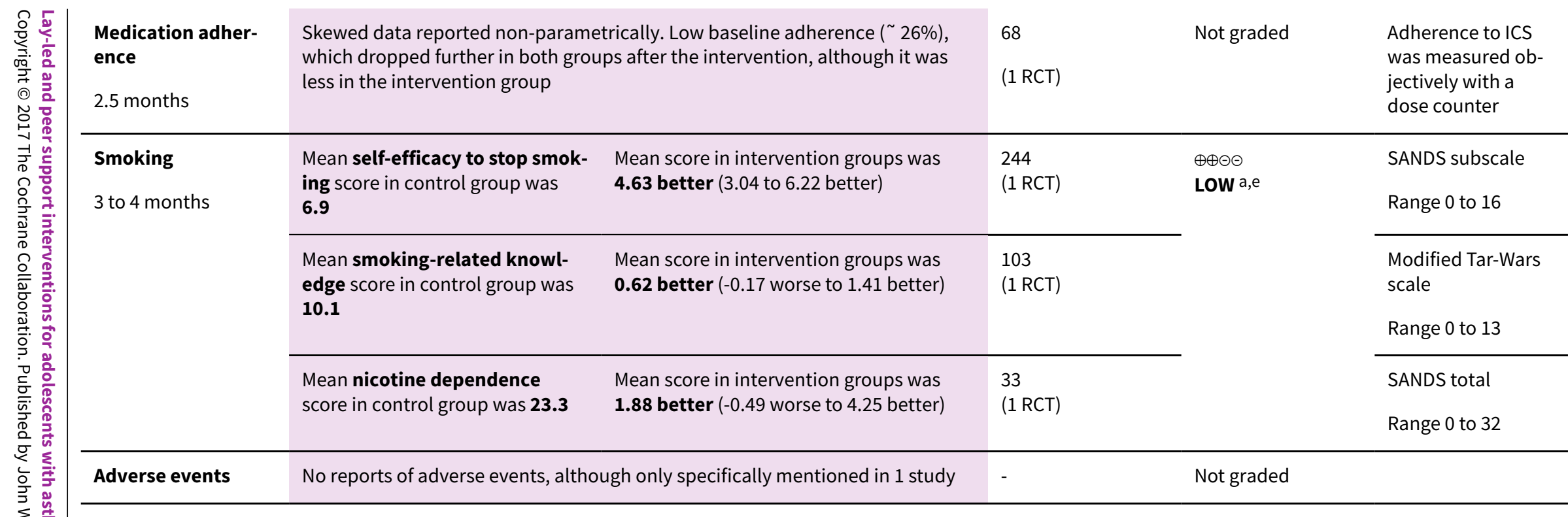

${ }^{*}$ The basis for the assumed risk (e.g. median control group risk across studies) is provided in footnotes. The corresponding risk (and its $95 \%$ confidence interval) is based on assumed risk in the comparison group and the relative effect of the intervention (and its $95 \% \mathrm{Cl}$ ).

ACQ: asthma control questionnaire; ACT: asthma control test; CI: confidence interval; ICS: inhaled corticosteroid; MCID: minimal clinically important difference; PAQLQ: Paediatric Asthma Quality of Life Questionnaire; RCT: randomised controlled trial; RR: risk ratio; SANDS: Self-Administered Nicotine Dependence Scale.

GRADE Working Group grades of evidence.

High quality: We are very confident that the true effect lies close to the estimate of effect.

Moderate quality: We are moderately confident in the effect estimate: The true effect is likely to be close to the estimate of effect but may be substantially different.

Low quality: Our confidence in the effect estimate is limited: The true effect may be substantially different from the estimate of effect.

Very low quality: We have very little confidence in the effect estimate: The true effect is likely to be substantially different from the estimate of effect.

aDowngraded for risk of bias. Outcome measured on a self-rated scale. Likely to be affected by both performance and detection biases.

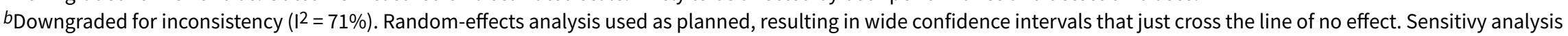
with a fixed-effect model showed much tighter Cls around a mean difference of 0.16 ( 0.06 to 0.26$)$. Not downgraded for imprecision.

c Confidence intervals favour the intervention, but the effect is based on one study of 251 people (downgraded for imprecision).

${ }^{d}$ Two other studies reported the measure but did not plan a responder analysis (not downgraded for publication bias).

eDowngraded for imprecision. Point estimates favoured the intervention, but lower confidence limits do not rule out possible harm. 


\section{B A C K G R O U N D}

\section{Description of the condition}

Asthma is a long-term respiratory disease that is characterised by reversible breathing difficulties due to narrowing of the airways, thickening of the airway walls and increased mucus production (GINA 2016). Common symptoms include wheezing, shortness of breath, chest tightness and cough, and diagnosis is established on the basis of medical history and investigations such as spirometry, peak flow diaries, reversibility, biomarkers or methacholine challenge (GINA 2016). Asthma is a prevalent disease that affects more than 334 million people worldwide, with direct treatment costs and indirect costs to society among the highest for non-communicable diseases (Global Asthma Network 2014). Incidence varies according to many factors, including age, country, sex and smoking exposure, but has been estimated recently at 10.2 per 1000 person-years among Canadian adolescents (Lawson 2014). Asthma is a significant cause of avoidable morbidity and mortality for patients and families in developed countries, and asthma accounts for many lost working days (GINA 2016; Global Asthma Network 2014; NRAD 2014), especially in low- and middleincome countries, where the condition often is undiagnosed and untreated (Global Asthma Network 2014).

Adults and adolescents generally are considered similar in terms of diagnosis and pharmacological treatment for asthma, but symptom type, frequency and severity vary significantly over time and between people (BTS/SIGN 2016). Adolescents may have different needs and preferences compared with children and adults; the clinician must consider this when providing care (Koster 2015). Adolescents are more likely to have anxiety and depression and to engage in smoking and recreational drug use, both of which may exacerbate their asthma (Bender 2006). Furthermore, adolescents with asthma are more likely to under-report symptoms and to exhibit poor adherence to maintenance inhalers (Bender 2006).

\section{Description of the intervention}

Peer support is a general term that may apply to many types of interventions for which the common factor is participation of a person or people similar to those for whom the intervention is provided. One concept analysis fully defined peer support as "the provision of emotional, appraisal and informational assistance by a created social network member who possesses experiential knowledge of a specific behaviour or stressor and similar characteristics as the target population" (Dennis 2003). Peer support interventions may be aimed at individuals or conducted in groups, with goal of improving well-being and enhancing disease management by sharing experiences and information with those who have been through similar experiences.

Lay-led interventions may overlap significantly with what is considered peer support, but they may not necessarily be led by people with asthma or other chronic conditions. Interventions may be led by 'patient experts' to be condition-specific, such as the Arthritis Self-Management Program (Lorig 1986), or may be designed to be applicable to various chronic conditions, such as the Chronic Disease Self-Management Program (Lorig 2001) and the Expert Patients Programme (Department of Health 2001). The person who delivers the intervention might be considered a 'lay' person or a peer, or both, depending on the person's age, profession and health status in relation to the target population. For example, if adolescents with asthma are the target population, an adolescent with or without asthma and an adult with asthma might be considered peers, as might individuals of any age with a different long-term condition. In all of these cases, leaders do not receive formal medical training and can be considered 'lay' people as well, whereas an adult without asthma or another health condition might only fit into the category of a lay leader. Delivery of asthma self-management education through lay leaders, regardless of their own health status and similarity to the target population, can be as effective as that delivered by practice nurses (Partridge 2008). Peer and lay leaders may often fall under the term 'community health workers' - a role that is increasingly adopted as a way of improving outreach and promoting healthy behaviour, particularly among high-risk populations in lower-resource settings (Butz 1994; Haines 2007).

Peer support and lay-led interventions may vary substantially regarding the number and content of sessions, the degree of structure within the intervention, locations at which sessions are conducted and individuals presenting the sessions. Recent studies have capitalised on adolescents' familiarity with communication technologies and social networking as a way of delivering peer support interventions (NCT01169883; Stewart 2013). Asthma treatment guidelines now recognise peer-led and peer support education as ways to complement the usual clinician-based care to address poor adherence among adolescents (BTS/SIGN 2016; GINA 2016), although they do not elaborate on the content or method of delivery of such interventions.

\section{How the intervention might work}

Dennis 2003 describes three types of support that are common to most peer support interventions and the ways they are likely to improve the lives of people in the context of health care. The first - emotional support - is thought to enhance self-esteem and self-efficacy by exchanging personal difficulties, empathy and reassurance with people in similar situations. The second - informational support - provides relevant factual information and advice that may help people engage in more effective selfmanagement, which is increasingly emphasised as a key factor in maintaining asthma control (NRAD 2014). The third - appraisal or "affirmational" support - helps people generate a positive outlook by discussing and receiving encouragement that one's thoughts and behaviours are normal and appropriate, with a view toward reducing the stigma of a long-term health condition.

Interventions led by 'patient experts' and lay people rather than by healthcare professionals may improve the rapport between leader and patient by removing the formality of traditional medical contacts, and by helping to engage people who normally would not visit their family physician or nurse. It is hoped that establishment of self-management and lay-led programmes in health care might "allow people with chronic diseases to have access to opportunities to develop the confidence, knowledge and skills to manage their conditions better, and thereby gain a greater measure of control and independence to enhance their quality of life" (Department of Health 2001). Increased social support for those living with asthma, specifically from parents or peers, has been associated with maintenance of a healthy lifestyle among adolescents, which may serve to reduce their exposure to unhealthy behaviours likely to exacerbate their symptoms (Yang 2010). However, interventions that are not led by 
trained medical professionals may have the opposite effect, for example, by sharing unsafe asthma management behaviours, or by advising about treatments without appropriate knowledge of their harms and benefits. Use of community health workers has highlighted the need for "focused tasks, adequate remuneration, training, supervision [and] evaluation" to document potential costeffectiveness and "to elucidate factors associated with success and sustainability" (Haines 2007).

\section{Why it is important to do this review}

The burden of asthma disability and mortality is greatest in the elderly and in adolescents between 10 and 14 years of age (Global Asthma Network 2014). Given higher engagement in risk-taking behaviours and the tendency to be reliant on and influenced by peers, it is important that health workers target adolescents by providing interventions that might improve adherence or reduce the likelihood of engaging in activities that will make their asthma worse (Bender 2006). It is also an important time to minimise school absence while establishing good self-management behaviours to be taken into adulthood.

The prevalence of mental health problems among adolescents with asthma has been associated with the increased burden of asthma symptoms and inability to cope with the disease (Richardson 2006) and makes adolescence an important time for optimal asthma care. The National Review of Asthma Deaths in the UK identified one or more avoidable factors that contributed to 17 of 18 deaths that occurred in individuals 10 to 19 years old during the year studied (NRAD 2014). Of these 18 deaths, poor adherence to medical advice was a contributing factor in 13 cases, psychosocial factors in four cases and smoke exposure in seven. Peer support or layled interventions may be provided to educate and motivate young people to avoid these factors, increase social support and reduce the stigma of asthma among adolescents.

\section{O B J E C T IVES}

To assess the safety and efficacy of lay-led and peer support interventions for adolescents with asthma.

\section{METHODS}

\section{Criteria for considering studies for this review}

\section{Types of studies}

We included parallel randomised controlled trials (RCTs). We included studies that used individual or cluster randomisation, but we excluded cross-over studies owing to the likelihood of carry-over effects. We included studies reported as full text, those published as abstract only and unpublished data.

\section{Types of participants}

We included adolescents with a diagnosis of asthma. We included studies that described inclusion criteria for asthma, such as confirmation by a physician or via spirometry, to exclude people with wheeze not associated with obstructive airways disease. For the purposes of this review, we defined adolescents as those between 10 and 19 years of age, in keeping with the definition of the World Health Organization (WHO 2016). If a study had an unclear age range, included a subset of the age group of interest (e.g. younger adolescents between 10 and 14 years of age) or included participants outside our predefined age criteria (e.g. university students 18 to 21 years of age), we included the study if the mean age of participants was between 10 and 19 years. We excluded studies that enrolled adolescents with other long-term conditions, such as cystic fibrosis, unless the study authors presented results for participants with asthma separately.

\section{Types of interventions}

We included studies that assessed an intervention delivered by peers or by lay people to adolescents with asthma. We defined peers as people who are not medically trained but are similar to the target population in terms of age, presence of an asthma diagnosis or diagnosis of a different long-term condition. These interventions may also be considered lay led, but other eligible interventions that meet the criteria for a lay-led intervention may not be considered to include peer support (e.g. those delivered by adult community health workers). We undertook meta-analyses only when interventions were similar enough for pooling to make sense, and we presented intervention characteristics in a summary table in the review. We explored differences in the characteristics of those who deliver the interventions, when possible, using subgroup analysis.

We analysed studies that compared the intervention versus usual care or a minimal control intervention separately from those that compared the intervention against another active intervention. We excluded studies that used basic peer support itself as a minimal control for a more intensive intervention. We included interventions delivered to individuals or groups of adolescents with asthma, irrespective of the mode of delivery (face-to-face or via technology). We excluded studies of interventions that involved multiple components other than the peer support or layled intervention unless the control group also received them.

We included studies regardless of the aim of the intervention (e.g. improving self-esteem, improving medication adherence, providing asthma education).

\section{Types of outcome measures}

\section{Primary outcomes}

1. Asthma-related quality of life (measured on a validated scale, e.g. Asthma Quality of Life Questionnaire (AQLQ))

2. Asthma exacerbations requiring at least a course of oral steroids

\section{Secondary outcomes}

1. Asthma control (measured on a validated scale e.g. Asthma Control Questionnaire (ACQ) or Asthma Control Test (ACT))

2. Unscheduled contacts with health services for asthma

3. Medication adherence

4. Smoking

5. Adverse events

Smoking is a behaviour that is commonly taken up in adolescence and is particularly risky for those with asthma. It was unclear in advance whether or how studies might measure this outcome (e.g. as mean frequency of cigarettes or people per group smoking by the end of the trial), but we summarised available information as a reduction in smoking may be an important benefit of peer support or lay-led interventions. 
Asthma exacerbations and unscheduled contacts with health services may occur as unintended adverse events of interventions not delivered by a healthcare professional, but higher rates of contact with health services may represent better preventative care. We were mindful of this when we interpreted these data.

Interventions may lead to other adverse outcomes, for example, from sharing of unsafe management behaviours or provision of incorrect advice. This may be reflected in the direction and magnitude of effect for several of the outcomes listed, but we analysed additional information about adverse events and safety issues when reported by study authors. We meta-analysed this information when possible, or we described it narratively, depending on the nature of the data.

We presented details about cost and resource implications of these interventions when available, but we did not conduct formal cost analyses.

Reporting one or more of the outcomes listed here in the study was not an inclusion criterion for this review. We used completion of study measurement as the main time point of interest, and we extracted and presented longer-term follow-up data when available.

\section{Search methods for identification of studies}

\section{Electronic searches}

We identified trials from the Cochrane Airways Group Specialised Register (CAGR), which is maintained by the Information Specialist for the Group. The Cochrane Airways Group Trials Register contains studies identified from several sources.

1. Monthly searches of the Cochrane Central Register of Controlled Trials (CENTRAL), through the Cochrane Register of Studies Online (crso.cochrane.org).

2. Weekly searches of MEDLINE Ovid SP (1946 to date).

3. Weekly searches of Embase Ovid SP (1974 to date).

4. Monthly searches of PsycINFO Ovid SP.

5. Monthly searches of the Cumulative Index to Nursing and Allied Health Literature (CINAHL) EBSCO.

6. Monthly searches of the Allied and Complementary Medicine Database (AMED) EBSCO.

7. Handsearches of the proceedings of major respiratory conferences.

Studies contained in the Trials Register are identified through search strategies based on the scope of the Cochrane Airways Group. We have presented details of these strategies, as well as a list of handsearched conference proceedings, in Appendix 1. See Appendix 2 for search terms used to identify studies for this review.

We also conducted searches of the clinical trials registries ClinicalTrials.gov (www.ClinicalTrials.gov) and the WHO International Clinical Trials Registry Platform (ICTRP; www.who.int/ ictrp/en/), using appropriately adapted search terms. We searched all databases from their inception to the present, and we imposed no restriction on language of publication.

We conducted the most recent searches on 25 November 2016.

\section{Searching other resources}

We checked the reference lists of all primary studies and review articles for additional references.

On 2 December 2016, we searched for errata or retractions from included studies published in full text on PubMed (www.ncbi.nlm.nih.gov/pubmed).

\section{Data collection and analysis}

\section{Selection of studies}

Two review authors (KK and RC or IC) independently screened titles and abstracts of all studies identified for possible inclusion as a result of the search and coded them as 'retrieve' (eligible or potentially eligible/unclear) or 'do not retrieve'. We retrieved full-text study reports/publications of articles that we coded as 'retrieve'. Two review authors (KK and RC or IC) independently screened these full-text articles and identified studies for inclusion, and identified and recorded reasons for exclusion of ineligible studies. We resolved disagreements through discussion. We identified and excluded duplicates and collated multiple reports of the same study, so that each study rather than each report was the unit of interest in the review. We recorded the selection process in sufficient detail to complete a Preferred Reporting Items for Systematic Reviews and Meta-Analyses (PRISMA) flow diagram and a Characteristics of excluded studies table (Moher 2009).

\section{Data extraction and management}

To record study characteristics and outcome data, we used a data collection form that we had piloted on at least one included study in the review. One review author (KK) extracted the following study characteristics from the included studies.

1. Methods: study design, total duration of study, details of any 'run-in' period, number of study centres and locations, study setting, withdrawals and date of study.

2. Participants: N, mean age, age range, gender, severity of condition, diagnostic criteria, baseline lung function, smoking history, inclusion criteria and exclusion criteria.

3. Interventions: intervention, comparison, concomitant medications, excluded medications, costs and resources involved.

4. Outcomes: primary and secondary outcomes specified and collected and time points reported.

5. Notes: funding for trial and notable conflicts of interest of trial authors.

Two review authors (KK and RC or IC) independently extracted outcome data from the included studies. We noted in the Characteristics of included studies table if study authors did not report outcome data in a useable way. We resolved disagreements by consensus. One review author (KK) transferred data into the Review Manager (RevMan) file (RevMan 2014). We double-checked that data were entered correctly by comparing data presented in the systematic review against the study reports. A second review author (RC) spot-checked study characteristics for accuracy against the study reports.

\section{Assessment of risk of bias in included studies}

Two review authors (KK and RC or IC) independently assessed the risk of bias for each included study using the criteria 
outlined in the Cochrane Handbook for Systematic Reviews of Interventions (Higgins 2011). We resolved disagreements by discussion and assessed risk of bias according to the following domains.

1. Random sequence generation.

2. Allocation concealment.

3. Blinding of participants and personnel.

4. Blinding of outcome assessment.

5. Incomplete outcome data.

6. Selective outcome reporting.

7. Other bias.

We graded each potential source of bias as high, low or unclear and provided a quote from the study report together with a justification for our judgement in the 'Risk of bias' table. We summarised 'Risk of bias' judgements across studies for each of the domains listed. We considered blinding separately for different key outcomes when necessary (e.g. for unblinded outcome assessment, risk of bias for all-cause mortality may be very different than for a patientreported pain scale). When information on risk of bias was related to unpublished data or correspondence with a trial author, we noted this in the 'Risk of bias' table.

When considering treatment effects, we took into account the risk of bias for studies that contributed to these outcomes.

\section{Assessment of bias in conducting the systematic review}

We conducted the review according to this published protocol and reported deviations from it in the Differences between protocol and review section of the systematic review.

\section{Measures of treatment effect}

We analysed dichotomous data as odds ratios (OR) and continuous data as mean differences (MD) or standardised mean differences (SMD). We entered data presented as a scale with a consistent direction of effect.

We undertook meta-analysis only when this was meaningful (i.e. if treatments, participants and the underlying clinical question were similar enough for pooling to make sense).

We narratively described skewed data reported as medians and interquartile ranges.

When study authors reported multiple trial arms in a single trial, we included only the relevant arms. If we combined two comparisons (e.g. two types of peer support vs a minimal control intervention) in the same meta-analysis, we halved the control group to avoid double-counting.

If adjusted analyses of variance or co-variance (ANOVA or ANCOVA) were available, we used these in our meta-analyses. If both change from baseline and endpoint scores were available for continuous data, we used change from baseline unless most studies reported endpoint scores. If a study reported outcomes at multiple time points, we used the end of study measurement.

When both an analysis including only participants who completed the trial and an analysis that imputed data for participants who were randomly assigned but did not provide end point data (e.g. last observation carried forward) were available, we used the latter.

\section{Unit of analysis issues}

For dichotomous outcomes, we used participants, rather than events, as the unit of analysis (i.e. number of children admitted to hospital, rather than number of admissions per child). We metaanalysed data from cluster RCTs only if available data had been adjusted (or could be adjusted) to account for the clustering.

\section{Dealing with missing data}

We contacted investigators or study sponsors to verify key study characteristics and to obtain missing numerical outcome data when possible (e.g. when we identified a study as an abstract only). When this was not possible, and we considered the missing data to have introduced serious bias, we explored the impact in the Grading of Recommendations Assessment, Development and Evaluation (GRADE) rating for that outcome.

\section{Assessment of heterogeneity}

We used the $1^{2}$ statistic to measure heterogeneity among the studies in each analysis. If we identified substantial heterogeneity, we reported this and explored possible causes by conducting prespecified subgroup analysis.

\section{Assessment of reporting biases}

We were not able to pool more than 10 studies, so we could not create and examine a funnel plot to explore possible small study and publication biases.

\section{Data synthesis}

We used a random-effects model and performed a sensitivity analysis based on a fixed-effect model.

\section{'Summary of findings' table}

We created Summary of findings for the main comparison using all outcomes listed in this protocol. We used the five GRADE considerations (study limitations, consistency of effect, imprecision, indirectness and publication bias) to assess the quality of a body of evidence as it relates to studies that contributed data to the meta-analyses for prespecified outcomes. We used methods and recommendations described in Section 8.5 and Chapter 12 of the Cochrane Handbook for Systematic Reviews of Interventions (Higgins 2011), and we used the GRADEpro Guideline Development Tool (GDT) software (GRADEpro GDT). We justified all decisions to downgrade or upgrade the quality of the evidence using footnotes, and we made comments to aid the reader's understanding of the review when necessary.

\section{Subgroup analysis and investigation of heterogeneity}

We planned the following subgroup analyses for primary outcomes.

1. Group versus one-to-one interventions.

2. Person delivering the intervention (e.g. peer supported by an adolescent vs lay led by an adult).

3. Face-to-face versus remotely delivered interventions (e.g. over the Internet, by telephone).

We used the formal test for subgroup interactions provided in RevMan (RevMan 2014).

We did not intend to conduct a formal subgroup analysis on the basis of age unless studies used age criteria that do not overlap (e.g. 
10 to 14 years of age and 15 to 19 years of age). Studies may recruit adolescents from a range of ages that would not fit predefined arbitrary categories.

We presented key characteristics of study populations and interventions in an additional table to display other potential sources of heterogeneity that could not be easily assessed in subgroups (Table 1), and we described key characteristics in the review text (e.g. mean age, healthcare setting, measures of asthma severity, frequency and duration of sessions, baseline social support).

\section{Sensitivity analysis}

We planned the following sensitivity analyses by removing the following from the primary analyses.

1. Studies at high risk of selection bias (judgement of high risk for either of the selection bias domains).

2. Unpublished data (provided by study authors or derived from non-peer-reviewed sources such as conference abstracts).
3. Studies that include a subset of ineligible participants (e.g. those younger or older than the predefined population).

\section{RES U L T S}

\section{Description of studies}

\section{Results of the search}

We identified 126 records through electronic database searches and an additional nine through other resources. We removed five duplicates and sifted the remaining 130 unique records. We excluded 89 by reviewing titles and abstracts alone because it was obvious they were not relevant to the research question. We obtained full texts for the remaining 41 and excluded 20 because they did not meet the inclusion criteria. One study met the inclusion criteria but is ongoing (NCT02293499). Sixteen records met all inclusion criteria and could be collated into five included studies (Al-sheyab 2012; NCT01938976; NCT01169883; NCT01161225; Shah 2001). Figure 1 illustrates the process of study selection. 
Figure 1. Study flow diagram.

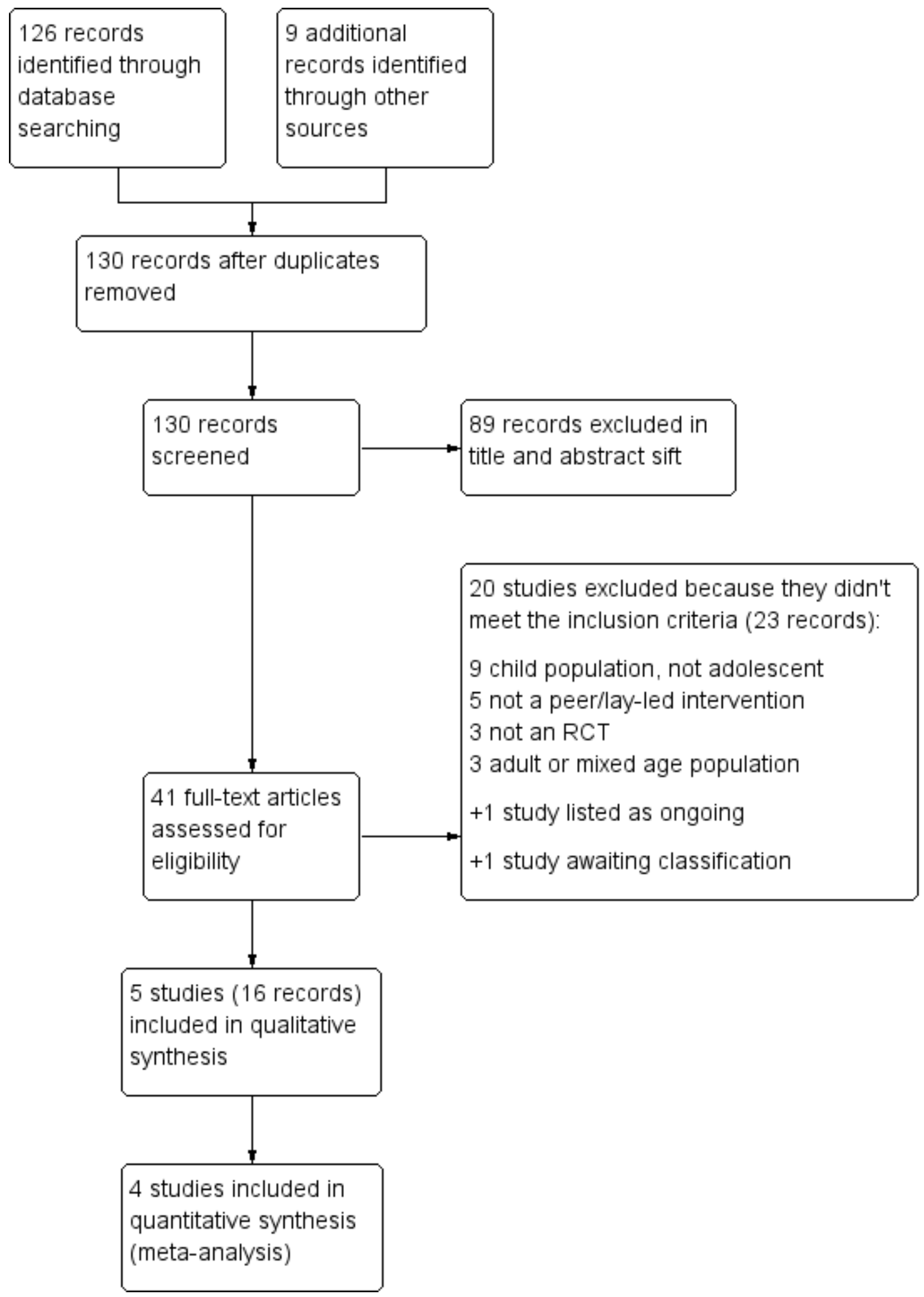


Although one study identified through clinicaltrials.gov met the inclusion criteria, we have listed it as awaiting classification because we found no results or publications posted (NCT00217776). We tried to make contact with the study team, but the lead investigator is now deceased. This 12-month study, which is registered in the USA, is described as double-blind and aimed to recruit 1292 younger adolescents between 11 and 12 years of age. Investigators designed this study to test addition of peer asthma education to the Open Airways programme.

\section{Included studies}

Five studies, including a total of 1146 participants, met the inclusion criteria for this review (Al-sheyab 2012; NCT01938976; NCT01169883; NCT01161225; Shah 2001). We have provided a summary of study, participant and intervention characteristics in Table 1, and have given additional details about each individual study and risk of bias in the Characteristics of included studies tables. Four studies contributed to at least one meta-analysis, and one was described narratively (NCT01169883).

Three studies had a cluster randomised design (Al-sheyab 2012; NCT01938976; Shah 2001), and two studies randomised individuals to receive intervention or control (NCT01169883; NCT01161225). The number of adolescents included within a study ranged from 68 to 433 (median 261). The three cluster trials randomised four (Al-sheyab 2012; NCT01938976) or six schools (Shah 2001). Two studies took place in Jordan (Al-sheyab 2012; NCT01938976), two in the USA (NCT01169883; NCT01161225) and one in Australia (Shah 2001). Three studies provided interventions through schools (Al-sheyab 2012; NCT01938976; Shah 2001), one at a day camp (NCT01161225) and one through primary care (NCT01169883). Studies lasted between 2.5 and 9 months.

\section{Population characteristics and inclusion criteria}

Lower age limits ranged from 11 to 14 and upper limits from 13 to 17 (Table 1). Al-sheyab 2012 and NCT01938976 did not report mean age, but means in other studies ranged from 12.5 to 15.5 years. Four studies recruited roughly equal proportions of males and females ( $42.8 \%$ to $56.3 \%)$, and one study specifically recruited from boys' schools (NCT01938976). Studies offered very little information about ethnicity; NCT01169883 specifically recruited adolescents who self-identified as African American or Hispanic, and around $45 \%$ of participants in NCT01161225 were white. Studies excluded adolescents who could not read or write or were not capable of participating in the intervention, along with anyone with another major disease that would affect their questionnaire responses.

In three studies, all recruited participants had a diagnosis of asthma or reported asthma symptoms (NCT01169883; NCT01161225; Shah 2001), and two studies recruited participants for whom some outcomes were measured in the subset with a diagnosis of asthma (Al-sheyab 2012; NCT01938976). Severity of asthma and how it was described varied; less than a third of participants in Al-sheyab 2012 and Shah 2001 were taking a daily inhaled corticosteroid (ICS), as was everyone in NCT01169883 and $71 \%$ of participants in NCT01161225. NCT01169883 required that participants have a current ICS prescription and excluded those with adherence above $48 \%$ (measured objectively over 14 days at baseline with an electronic dose counter), as the intervention was aimed at improving adherence. This study recruited a population with relatively severe persistent asthma compared with participants in the other studies; around $80 \%$ had uncontrolled asthma and around half had one or more emergency department (ED) or hospital visits over the past year.

Smoking varied across studies; around a quarter of participants in Al-sheyab 2012 were current smokers, and nearly three-quarters had a family member who smoked. Smoking was much less prevalent in NCT01169883 at less than 5\% of participants and less than $10 \%$ of family members, and $37 \%$ of the population in NCT01938976 were 'ever smokers'.

\section{Interventions and comparisons}

Three studies used the Triple A programme, which stands for "Adolescent Asthma Action" (Al-sheyab 2012; NCT01938976; Shah 2001). Triple A is a three-step programme that teaches older students to educate and empower their peers about asthma and its management. Teaching tools include games, videos, worksheets, discussions and role-plays. In step 1 volunteers take part in a one day workshop and are trained to become Triple A Peer Leaders. In step 2, small teams of peer leaders conduct health lessons in schools, and in step 3, participants develop and present key messages to other students. In Al-sheyab 2012, bilingual (English and Arabic) Jordanian health workers delivered the programme. Peers were year 11 students, and participants were year 10 students. The control group received no intervention. NCT01938976 tested the addition of a smoke-free pledge to the Triple A programme; peers in that study were in grade 10, and participants were in grades 7 and 8. Shah 2001 trained year 11 peers, and both intervention and control groups received various input from school staff and local doctors.

NCT01169883 delivered an intervention that consisted of peer support group sessions and mp3 messaging. Social workers trained to use motivational interviewing led the sessions. During each session, participants developed and recorded messages to be played between music tracks to encourage ICS adherence. The attention control condition included weekly individual sessions with a research assistant and adherence promotion messages recorded by an asthma physician.

The intervention group in NCT01161225 attended a one-day camp, with group activities facilitated by 12 peer leaders. Peers were 16 to 20 years old, attended three-week intensive structured training sessions and facilitated activities in small groups of 6 to 10 campers, overseen by adults. Three 45- to 60-minute sessions based on the Power Breathing ${ }^{\mathrm{TM}}$ program covered basic asthma education, psychosocial issues and asthma self-management. Group activities involved discussion, strategic thinking, knowledgetesting games and role playing. At completion of the camp, peer leaders conducted monthly phone follow-ups to provide continuous peer support and encouragement using a checklist. The control group attended a day camp, during which healthcare practitioners presented asthma education at the same camp site on different days.

\section{Excluded studies}

After viewing the full texts, we excluded 20 studies because they did not meet the inclusion criteria. Reasons for exclusion were child rather than adolescent population (Bryant-Stephens 2008; Chernoff 2002; Flores 2009; Horner 2008; Krieger 2009; NCT02747706; Pulgaron 2010; Rice 2015; Valery 2010); intervention not peer supported or lay led (Bruzzese 2008; Duncan 2013; Martin 2015; Srof 2012; Wallis 2015); not an RCT (Gibson 1998; JPRN- 
UMIN000018186; Mosnaim 2010); and adult or mixed age study population (NCT00214669; NCT01725815; Partridge 2008). selection and attrition biases. We have summarised risk of bias judgements across studies in Figure 2.

\section{Risk of bias in included studies}

Most of our concerns for the five included studies were related to blinding and reporting biases. Studies generally controlled well for

Figure 2. Risk of bias summary: review authors' judgements about each risk of bias item for each included study.

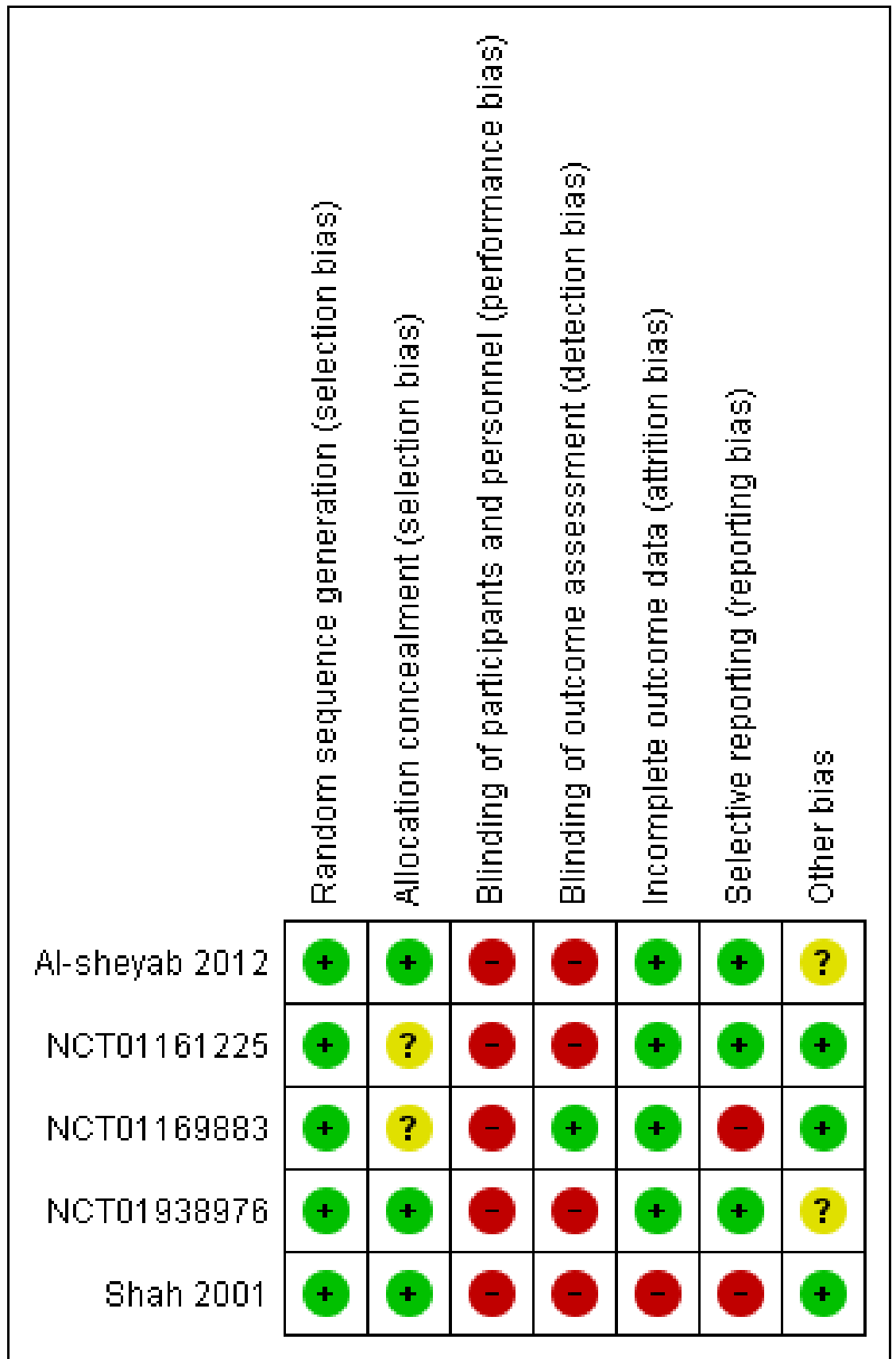

\section{Allocation}

All five studies used appropriate methods of generating the random sequence to allocate participants to groups; thus we rated them as having low risk of bias. Three studies also described methods of allocation concealment at the point of randomisation (Al-sheyab
2012; NCT01938976; Shah 2001), but the other two studies did not describe these methods in adequate detail, so we rated them as having unclear risk (NCT01169883; NCT01161225). 


\section{Blinding}

We considered all studies to have high risk of performance bias because the interventions were behavioural and could not be blinded. Knowledge of group allocation, regardless of outcomes measured, may have inadvertently affected how study investigators or participants in each group behaved, which may have biased the results. However, this may have been less of an issue in studies in which the control group also received an intervention, such as the adult-led day camp in NCT01161225, the active control in NCT01938976 and healthcare professional input in Shah 2001.

It was possible to blind outcome assessors in all studies, but not for outcomes rated by the individual or by people who were aware of group allocation. NCT01169883 specifically described measures to blind outcome assessors, but the other studies did not. For this reason, we rated risk as high in all studies except NCT01169883 owing to the types of outcomes reported, but we considered this separately for each outcome when applying the GRADE framework.

\section{Incomplete outcome data}

We rated four studies as having low risk of attrition bias because of the extent of dropout and imbalance between groups (Al-sheyab 2012; NCT01938976; NCT01169883; NCT01161225). We rated Shah 2001 as high risk because the study reported only the number of participants who had matched data among those with baseline measurements, rather than among the total number of participants with asthma in the randomised schools. Study authors state that missing data were due to misclassification, a change in students' schools or absence on the day of testing or failure to complete the questionnaire, but it is unclear how these reasons compared between groups.

\section{Selective reporting}

We rated two studies as having high risk of bias because some researchers reported some results relevant to this review in insufficient detail for inclusion in the meta-analysis (NCT01169883; Shah 2001). This usually occurred when results were reported narratively as non-significant or graphically without the numerical data required for pooling with other studies, or when outcomes mentioned in the methods were not reported in the results. We rated NCT01161225 as low risk because the trial was prospectively registered and publications reported all prespecified outcomes. We also rated Al-sheyab 2012 and NCT01938976 as low risk; although these studies were not prospectively registered, study authors responded to our contact and confirmed that they possessed no additional data that were relevant to our analyses.

\section{Other potential sources of bias}

Al-sheyab 2012 described school selection in detail but may have introduced a selection bias before randomisation. NCT01938976 used the split-plot design to adjust outcome analyses for clustering effects as well as for baseline differences between groups.

\section{Effects of interventions}

\section{See: Summary of findings for the main comparison}

We have summarised all results and have displayed GRADE quality ratings in Summary of findings for the main comparison. Table footnotes list factors that decreased our confidence in study findings; we have explained these in greater detail in the discussion (Quality of the evidence).

\section{Primary outcomes}

\section{Asthma-related quality of life}

Three studies reported mean change in asthma-related quality of life using the paediatric version of the Asthma Quality of Life Questionnaire (PAQLQ) (Al-sheyab 2012; NCT01161225; Shah 2001). The mean difference (MD) observed with the prespecified randomeffects model was 0.40 ( $95 \%$ confidence interval ( $\mathrm{Cl})-0.02$ to 0.81 ). Results revealed significant statistical heterogeneity because the effect in Shah 2001 was much smaller than that described in the other two studies. When we used a fixed-effect model, the effect size was much smaller and the confidence intervals tighter (MD $0.16,95 \% \mathrm{Cl} 0.06$ to 0.26 ). We used the longest time point available for each study, and sensitivity analyses based on the shorter time points available in NCT01161225 did not change our conclusions.

Shah 2001 also reported a responder analysis showing that more participants in the intervention group had an improvement of at least 0.5 points in their quality of life score (the minimal clinically important difference on the PAQLQ); $25 \%$ of those who received peer support responded compared with $12 \%$ of those in the control group (odds ratio (OR) 2.34, 95\% Cl 1.21 to 4.55; 251 participants; one study).

\section{Asthma exacerbations requiring at least a course of oral steroids}

None of the data on asthma exacerbations were suitable for meta-analysis. Shah 2001 reported exacerbations narratively as follows: "The proportion of students reporting asthma attacks at school in year 10 increased in the control group $(21.2 \% \mathrm{v}$ $34.8 \%)$. No change was found in the intervention group $(24.2 \%$ v $25.8 \%$ ). The intervention had no effect on school absenteeism and asthma attacks in year 7 students". Al-sheyab 2012 and NCT01938976 confirmed that investigators received no reports of asthma exacerbation during these studies.

\section{Secondary outcomes}

\section{Asthma control}

Two studies used a measure of asthma control; NCT01938976 used the Asthma Control Test (ACT, range of scores 5 to 23), and NCT01161225 used the Asthma Control Questionnaire (ACQ, range of scores 4 to 16 ).

We did not pool results because comparisons made in these studies were not similar; NCT01938976 tested a smoking pledge added to the Triple A programme versus Triple A alone, and NCT01161225 compared a peer-led intervention versus one delivered by adults. NCT01938976 found a mean difference on the ACT of 0.50 favouring the smoking pledge ( $95 \% \mathrm{Cl}-0.61$ to 1.61 ), and NCT01161225 found a mean difference on the ACQ of 0.65 favouring peer-led over adult-led interventions $(95 \% \mathrm{Cl}-0.14$ to 1.44$)$. Neither effect was statistically significant.

\section{Unscheduled contacts with health services for asthma}

NCT01161225 was the only study that reported the effect of a peer-led intervention on the need for unscheduled visits to a healthcare provider. Investigators measured this outcome at nine months as the mean number per participant over the previous three months, but the data were skewed, so we did not calculate a 
mean difference. The 43 adolescents in the intervention group had a mean of 0.53 exacerbations each (standard deviation (SD) 1.12), and the 41 adolescents in the control group had a mean of 0.78 exacerbations each (SD 1.27). Al-sheyab 2012 and NCT01938976 confirmed to us that no one needed urgent care during these studies.

\section{Medication adherence}

NCT01169883 was specifically aimed at improving adherence and was the only study to report this as an outcome. Researchers measured adherence to inhaled steroids objectively using an electronic dose counter as average daily adherence over 14 days at the 10-week endpoint.

We did not present the data on a forest plot as they were skewed and were analysed by study authors as medians and interquartile ranges (IQRs). Baseline adherence to inhaled steroids was very low at $27.4 \%$ in the peer support group (IQR 14.3 to 35.0 ) and $25.9 \%$ in the control group (IQR 14.0 to 37.5). After 10 weeks, median adherence had dropped even lower in both the peer support group (median 7.1\%; IQR 0.9 to 21.4) and the control group (median $14.3 \%$; IQR 5.4 to 21.4 ).

\section{Smoking}

Two studies reported smoking outcomes (Al-sheyab 2012; NCT01938976); one of these specifically tested the effect of a smoking pledge added to a peer intervention (NCT01938976). Results are presented on one forest plot but have not been pooled. Al-sheyab 2012 reported self-efficacy to stop smoking on a subscale of the Self-Administered Nicotine Dependence Scale (SANDS; Alanasari 2004; Davis 1994). NCT01938976 reported the total nicotine dependence score on the SANDS, as well as a measure of smoking-related knowledge (Cain 2006). All point estimates favoured the intervention, but only results on the self-efficacy scale in Al-sheyab 2012 showed a statistically significant result over those in the control group (MD 4.63, 95\% Cl 3.04 to $6.22 ; 0$ to 16 subscale, higher scores better); results for asthma-related knowledge (MD $0.62,95 \% \mathrm{Cl}-0.17$ to $1.41 ; 0$ to 13 scale; higher scores better) and nicotine dependence measured on the SANDS (MD 1.88, 95\% Cl -0.49 to 4.25 ; 0 to 32 scale; higher scores better) favoured peer support, but confidence intervals did not rule out the possibility of no difference.

\section{Adverse events}

NCT01161225 was the only study that reported adverse events, stating that no serious or non-serious adverse events occurred in either group.

\section{Subgroup and sensitivity analyses}

It was not possible to conduct any planned subgroup analyses owing to the small number of studies reporting the outcomes of interest and the differences between comparisons made. Therefore, we were not able to test for possible moderating effects of interventions delivered in groups versus one-on-one, the person delivering the intervention or face-to-face versus remotely delivered interventions.

We rated no studies as having high risk of bias for either of the selection bias domains, so no sensitivity analysis was needed. Neither did we include unpublished data or studies that included a subset of ineligible participants, so these sensitivity analyses also were not necessary.

\section{DISCUSSION}

\section{Summary of main results}

Five studies including a total of 1146 participants met the inclusion criteria for this review. As ever with systematic reviews of complex interventions, studies varied by design (cluster and individually randomised), duration (2.5 to 9 months), setting (school, day camp, primary care) and intervention content. Most risk of bias concerns were related to blinding and incomplete reporting, which limited the meta-analyses that could be performed. Studies generally controlled well for selection and attrition biases.

All participants were between 11 and 17 years of age. Asthma diagnosis and severity varied, as did smoking prevalence. Three studies used the Triple A programme (Al-sheyab 2012; NCT01938976; Shah 2001), one of which tested the addition of a smoke-free pledge. NCT01169883 delivered peer support group sessions and $\mathrm{mp} 3$ messaging to encourage adherence, and NCT01161225 compared a peer-led asthma day camp versus an equivalent session led by healthcare practitioners.

We had low confidence in all study findings owing to risk of bias, inconsistency and imprecision. Results from an analysis of asthmarelated quality of life conducted through the prespecified randomeffects model were imprecise and showed no difference (mean difference (MD) $0.40,95 \%$ confidence interval ( $\mathrm{Cl}$ - -0.02 to 0.81 ); a sensitivity analysis based on a fixed-effect model and a responder analysis in Shah 2001 suggested possible benefit. Most other results were summarised narratively and generally did not show an important benefit of the intervention; studies yielded no analysable data on asthma exacerbations or unscheduled visits (which were skewed), and one study measuring adherence noted a drop in both groups. Effects on asthma control favoured the intervention but were not statistically significant. Results from two studies with high levels of baseline smoking showed promising results for selfefficacy to stop smoking, but overall nicotine dependence and smoking-related knowledge were not significantly better in the intervention group. Investigators reported no adverse events.

\section{Overall completeness and applicability of evidence}

We designed this review to focus on adolescents as a high-risk group, and although this allowed us to be more specific and results to be more applicable, it means that the evidence base for younger children has not been considered (see Agreements and disagreements with other studies or reviews). This focus means led to identification of only five relevant studies, although we are aware of two more in the pipeline. One, listed as an ongoing study (NCT02293499), is testing a peer-led programme for asthma self-management in adolescents, and is aiming to recruit 420 adolescents. The second was flagged by the author of NCT01161225, a larger replication and extension study in inner-city schools. We will include both of these studies in a future update of this review.

It is possible that these interventions may best target higherrisk populations, in terms of the background of the adolescents or the severity of their asthma, but it is difficult to tease out these moderating factors from the current evidence base. It has been suggested that boys, non-white adolescents and those from 
lower socioeconomic backgrounds may benefit more from these interventions (Al-Sheyab 2012, commentary on NCT01161225), but this review cannot substantiate these claims without receiving individual patient data. Both NCT01169883 and NCT01161225 looked into these issues; results are helpful for informing where future research should be directed, but associations are usually observational and may be tied to the specific contexts in which these studies were conducted. Non-randomised and feasibility studies may supplement the randomised evidence base to inform whether peer support and lay-led interventions are likely to be costeffective, and for whom.

As is often the case with reviews of complex interventions, variation in the characteristics of interventions evaluated makes it difficult to assess their general applicability, or to pick out particularly successful aspects of interventions to aid implementation. At present, evidence is insufficient to conduct subgroup analyses that would tell us whether a group format is more effective than a oneon-one approach, whether it matters who delivers the intervention and whether interventions delivered remotely (e.g. over the phone, by Internet) are as successful as face-to-face support.

\section{Quality of the evidence}

When we were able to apply the GRADE framework, we rated evidence as low quality, meaning that our confidence in the effect estimates is limited. We did not apply GRADE to unscheduled visits, medication adherence or adverse events because results were not pooled for these outcomes and were primarily described narratively. Nonetheless, our confidence in these results is very limited because they were not well reported or were skewed and were difficult to interpret as analysed in the published reports.

When we were able to grade estimates (quality of life, asthma control and smoking), we downgraded quality across the board for risk of bias. The most serious risk of bias for all graded outcomes involved lack of blinding, which, as previously described, may have influenced how participants and study personnel behaved or responded to questionnaires during the study. All graded outcomes were self-reported, which further increases the risk of bias because those filling in the questionnaires were aware of their treatment allocation and may have responded more or less favourably as a result. This may have been less of an issue in studies in which the control group received more than usual care, such as an alternative intervention or an attention control.

Our confidence in the estimates was also decreased by imprecision, which was related to the numbers of included studies and participants. For both asthma control and smoking, point estimates and most confidence intervals strongly favoured the intervention, but we could not rule out the possibility of no difference, or indeed that the control group saw greater benefit.

The pooled estimate for quality of life was very different depending on whether a random-effects or a fixed-effect model was used because statistical heterogeneity between study effects was great. All study point estimates favoured the intervention, so we were fairly confident in the direction of the effect, but we downgraded owing to inconsistency in the size of the effect; we did not downgrade for imprecision even though confidence intervals were wide with the random-effects model.

\section{Potential biases in the review process}

We prespecified the methods of this review in the published protocol (Kew 2016), and we carried out the review in accordance with this plan. In some instances, primarily owing to insufficient data, we were unable to carry out planned analyses; we have detailed these deviations in the section titled Differences between protocol and review. We minimised biases by carrying out study selection, data extraction and risk of bias assessments in duplicate; however, reflecting a change to the published protocol, this duplication was done by someone who was not part of the review team owing to time constraints.

Electronic and additional searches were broad and were repeated close to the time of publication of this review, so we feel confident that we have prepared a complete and up-to-date review of the relevant literature. We attempted to contact study authors for additional outcome data and to resolve uncertainties related to risk of bias. We received replies related to three studies (Al-sheyab 2012; NCT01938976; NCT01161225), which increased our confidence that we had not missed any relevant data measured in those studies.

\section{Agreements and disagreements with other studies or reviews}

To our knowledge, this is the first systematic review that brings together randomised evidence about lay-led and peer support interventions for adolescents with asthma. A fair amount of research has been conducted to look into the role of lay and peer support in some fields, particularly in mental health and cancer, and among prison populations (Bagnall 2015; Hoey 2008; Pfeiffer 2010), and for other specific purposes such as to support breastfeeding or to increase the uptake of immunisations (Glenton 2011; Kaunonen 2012). Researchers have placed less focus on the possible benefit of lay and peer workers for individuals with a chronic physical condition.

Raphael 2013 brought together evidence from 17 studies on the role of lay health workers in supporting children (0 to 18 years) with chronic conditions. Although the review looked for studies of children and adolescents with any chronic condition, review findings are broadly in agreement with our own. Synthesising evidence of complex interventions is difficult, and even more so when children with a range of conditions and varying needs are considered. Similar to our review, Raphael 2013 acknowledges the heterogeneity of interventions and provides a fairly narrative synthesis, concluding that the interventions "may lead to modest improvements in urgent care use, symptoms, and parental psychosocial outcomes". The Raphael review considers some studies excluded by our own that were conducted in younger populations (Bryant-Stephens 2008; Flores 2009; Krieger 2009). We came across several additional studies conducted in child rather than adolescent asthma populations (Chernoff 2002; Horner 2008; NCT02747706; Pulgaron 2010; Rice 2015; Valery 2010), suggesting that this has been more of a focus for researchers, but to date, no systematic review has examined this evidence.

We found some non-randomised evidence in the search, including a small feasibility study of children between 9 and 12 years of age that has not yet been published (JPRN-UMIN000018186), an impact evaluation of a peer-led asthma programme for adolescents (Gibson 1998) and an evaluation of the "Fight Asthma Now (FAN)" programme for 8- to 13-year-olds (Mosnaim 2010). These 
evaluations are useful for testing the feasibility of implementing programmes, and generally showed improvement in asthma knowledge and attitudes; effects on clinical outcomes and on quality of life are less certain, which is consistent with our findings.

\section{AUTHORS' CONCLUSIONS \\ Implications for practice}

Although weak evidence suggests that lay-led and peer support interventions could improve asthma-related quality of life for adolescents, benefits for asthma control, exacerbations and medication adherence remain unproven. As present, evidence is insufficient to show whether routine use of lay-led or peer support programmes in adolescent asthma care provides benefit.

\section{Implications for research}

Ongoing and future research - randomised and non-randomised - could help to identify target populations for lay-led and peer support interventions. By including subgroup and exploratory analyses or by focusing on particularly high-risk populations, researchers may be able to discern whether those with more severe asthma, those belonging to minority ethnic groups or those from lower socioeconomic backgrounds are more likely to benefit. Interventions aimed at influencing specific behaviours such as smoking and medication adherence could reveal what constitutes a successful intervention.

\section{ACKNOWLEDGEMENTS}

The Background and Methods sections of this review are based on a standard template used by the Cochrane Airways Group. We are very grateful to Elizabeth Stovold for designing the search strategy and to the Cochrane Airways Group staff for their editorial support.

We are very grateful for responses from study authors, Hyekyun Rhee and Nihaya Al-Sheyab.

Rebecca Normansell was the Editor for this review and commented critically on both the protocol and the full review and assisted with duplicate data extraction. 


\section{R E F E R E N C E S}

\section{References to studies included in this review}

Al-sheyab 2012 \{published data only\}

* Al-Sheyab N, Gallagher R, Crisp J, Shah S. Peer-led education for adolescents with asthma in Jordan: a cluster-randomized controlled trial. Pediatrics 2012;129(1):e106-12. [CENTRAL: 804288; CRS: 4900100000056279; PUBMED: 22157137]

Al-Sheyab NA, Shah S, Gallagher R, Crisp J. Effectiveness of a peer-led education program for adolescents with asthma in Jordanian schools [Abstract]. American Journal of Respiratory and Critical Care Medicine 2010;181(Meeting Abstracts):A2253. [CENTRAL: 756278; CRS: 4900100000025092]

\section{NCT01161225 \{published data only\}}

NCT01161225. Teen Asthma Project (TAP). clinicaltrials.gov/ ct2/show/NCT01161225 (first received 9 July 2010). [CRS: 4900132000030033]

\section{* Rhee H, Belyea MJ, Hunt JF, Brasch J. Effects of a peer-led asthma self-management program for adolescents. Archives of Pediatrics and Adolescent Medicine 2011;165(6):513-9. [CENTRAL: 793213; CRS: 4900100000026761; EMBASE: 2011309793]}

Rhee H, McQuillan BE, Belyea MJ. Evaluation of a peerled asthma self-management program and benefits of the program for adolescent peer leaders. Respiratory Care 2012;57(12):2082-9. [CENTRAL: 839956; CRS: 4900100000070664; EMBASE: 2012722950; PUBMED: 22710616]

Rhee H, Pesis-Katz I, Xing J. Cost benefits of a peer-led asthma self-management program for adolescents. Journal of Asthma 2012;49(6):606-13. [CENTRAL: 832704; CRS: 4900100000062830; EMBASE: 2012417278; PUBMED: 22758599]

NCT01169883 \{published data only\}

Mosnaim G, Li H, Martin M, Belice PJ, Avery E, Ryan N, et al. The use of coping peer support and $\mathrm{mp} 3$ technology to improve adherence to inhaled corticosteroids among lowincome minority adolescents. Journal of Allergy and Clinical Immunology 2013;131(2):AB133 [478]. [CENTRAL: 841332; CRS: 4900100000072731; EMBASE: 70984536]

* Mosnaim G, Li H, Martin M, Richardson D, Belice PJ, Avery E, et al. The impact of peer support and $\mathrm{mp} 3$ messaging on adherence to inhaled corticosteroids in minority adolescents with asthma: a randomized, controlled trial. Journal of Allergy and Clinical Immunology: In Practice 2013;1(5):485-93. [CENTRAL: 874493; CRS: 4900100000090940; EMBASE: 2013557461; PUBMED: 24565620]

NCT01169883. Coping peer intervention for adherence. clinicaltrials.gov/show/NCT01169883 (first received 23 July 2010). [CRS: 4900132000022879]

Powell L. The impact of peer support and $\mathrm{mp} 3$ messaging on adherence to inhaled corticosteroids in minority adolescents with asthma: a randomized, controlled trial. Journal of Allergy and Clinical Immunology 2013;1(5):485-93. [CENTRAL: 1051000; CRS: 4900126000026208; EMBASE: 24565620]
NCT01938976 \{published data only\}

Al-Sheyab N, Alomari M, Shah S, Gallagher R. 'Class smoke-free' pledge impacts on nicotine dependence in male adolescents: a cluster randomized controlled trial. Tropical Medicine and International Health 2015;20:255-6. [CENTRAL: 1106778; CRS: 4900132000012443; EMBASE: 72054834]

* Al-Sheyab N, Alomari MA, Shah S, Gallagher R. "Class smoke-free" pledge impacts on nicotine dependence in male adolescents: a cluster randomized controlled trial. Journal of Substance Misuse 2016;21(6):566-74.

NCT01938976. Efficacy of school-based, peer-led asthma and smoking prevention program on $\mathrm{CO} 1$ levels, nicotine dependence, and smoking behavior among early adolescents in Jordan. clinicaltrials.gov/show/NCT01938976 (first received 5 September 2013). [CRS: 4900132000030032]

\section{Shah 2001 \{published data only\}}

Shah S, Peat J, Cantwell G, Wang H, Sindusake P, Gibson P. Peerled asthma education improves quality of life in adolescents [abstract]. American Journal of Respiratory and Critical Care Medicine 2000;161(3 Suppl):A902. [CENTRAL: 429158; CRS: 4900100000014676]

Shah S, Peat J, Wang H, Sindusake P, Henry R, Gibson P. Peer-led asthma education improves quality of life in adolescents. Journal of Paediatrics and Child Health 2001;37(6):A2. [CENTRAL: 451330; CRS: 4900100000015641; 4900100000015641]

* Shah S, Peat JK, Mazurski EJ, Wang H, Sindhusake D, Bruce C, et al. Effect of peer led programme for asthma education in adolescents: cluster randomised controlled trial. BMJ (Clinical Research Ed.) 2001;322(7286):583-5. [CENTRAL: 328135; CRS: 4900100000009995; PUBMED: 11238152]

\section{References to studies excluded from this review}

\section{Bruzzese 2008 \{published data only\}}

Bruzzese JM, Unikel L, Gallagher R, Evans D, Colland V. Feasibility and impact of a school-based intervention for families of urban adolescents with asthma: results from a randomized pilot trial. Family Process 2008;47(1):95-113. [CENTRAL: 631279; CRS: 4900100000021863; PUBMED: 18411832]

\section{Bryant-Stephens 2008 \{published data only\}}

Bryant-Stephens T, Kurian C, Guo R, Zhao H. Impact of a household environmental intervention delivered by lay health workers on asthma symptom control in urban, disadvantaged children with asthma. American Journal of Public Health 2009;99(Suppl 3):S657-65. [CENTRAL: 731813; CRS: 4900100000024437; PUBMED: 19890172]

Bryant-Stephens T, Li Y. Outcomes of a home-based environmental remediation for urban children with asthma. Journal of the National Medical Association 2008;100(3):306-16. [CENTRAL: 631173; CRS: 4900100000021860; PUBMED: $18390024]$ 
Chernoff 2002 \{published data only\}

Chernoff RG, Ireys HT, DeVet KA, Kim YJ. A randomized, controlled trial of a community-based support program for families of children with chronic illness: pediatric outcomes. Archives of Pediatrics and Adolescent Medicine 2002;156(6):533-9. [CENTRAL: 380315; CRS: 4900100000011365 ; EMBASE: 2002199460; PUBMED: 12038883]

\section{Duncan 2013 \{published data only\}}

Duncan CL, Hogan MB, Tien KJ, Graves MM, Chorney JM, Zettler MD, et al. Efficacy of a parent-youth teamwork intervention to promote adherence in pediatric asthma. Journal of Pediatric Psychology 2013;38(6):617-28. [CENTRAL: 870963; CRS: 4900100000088253; EMBASE: 23248342; PUBMED: 23248342]

\section{Flores 2009 \{published data only\}}

Flores G, Bridon C, Torres S, Perez R, Walter T, Brotanek J, et al. Improving asthma outcomes in minority children: a randomized, controlled trial of parent mentors. Pediatrics 2009;124(6):1522-32. [CENTRAL: 728227; CRS: 4900100000024362; EMBASE: 2009639668; PUBMED: 19948624]

\section{Gibson 1998 \{published data only\}}

Gibson PG, Shah S, Mamoon HA. Peer-led asthma education for adolescents: impact evaluation. Journal of Adolescent Health 1998;22(1):66-72. [CENTRAL: 146910; CRS: 4900100000005938 ; PUBMED: 9436069]

\section{Horner 2008 \{published data only\}}

Horner SD, Fouladi RT. Improvement of rural children's asthma self-management by lay health educators. Journal of School Health 2008;78(9):506-13. [CENTRAL: 651040; CRS: 4900100000022529; 4900100000022529; PUBMED: 18786043]

\section{JPRN-UMIN000018186 \{published data only\}}

Feasibility and efficacy of peer education for children with asthma: a pilot study. https://upload.umin.ac.jp/cgi-openbin/ctr_e/ctr_view.cgi?recptno=R000020982 (accessed 12 September 2016).

\section{Krieger 2009 \{published data only\}}

Krieger J, Takaro TK, Song L, Beaudet N, Edwards K. A randomized controlled trial of asthma self-management support comparing clinic-based nurses and in-home community health workers: the Seattle-King County Healthy Homes II Project. Archives of Pediatrics and Adolescent Medicine 2009;163(2):141-9. [CENTRAL: 668378; CRS: 4900100000022903; EMBASE: 2009074863; 4900100000022903; PUBMED: 19188646]

\section{Martin 2015 \{published data only\}}

Martin MA, Mosnaim GS, Olson D, Swider S, Karavolos K, Rothschild S. Results from a community-based trial testing a community health worker asthma intervention in Puerto Rican youth in Chicago. Journal of Asthma 2015;52(1):59-70. [CENTRAL: 1000001; CRS: 4900126000018344 ; PUBMED: 25162304]

\section{Mosnaim 2010 \{published data only\}}

Mosnaim G, Sharp L, Damitz M, Li Z, Africk J, Powell LH. Evaluation of the fight asthma now (FAN!) program to improve asthma knowledge in urban youth and teenagers [Abstract]. Journal of Allergy and Clinical Immunology 2010;125(2 Suppl 1):AB59. [CENTRAL: 765101; CRS: 4900100000025609; EMBASE: 70155340]

\section{NCT00214669 \{published data only\}}

NCT00214669. Can education for South Asians with asthma and their clinicians reduce unscheduled care? A randomised trial (OEDIPUS). clinicaltrials.gov/ct2/show/NCT00214669 (first received 14 September 2005).

NCT01725815 \{published data only\}

NCT01725815. The health access and recovery peer program (HARP) [A peer-led, medical disease self-management program for mental health consumers]. clinicaltrials.gov/ show/NCT01725815 (first received 25 April 2012). [CRS: 4900132000006212]

\section{NCT02747706 \{published data only\}}

NCT02747706. Childhood asthma mentoring program for parents (CAMPP) [Peer mentor training to reduce hospitalizations for children with asthma]. clinicaltrials.gov/ show/NCT02747706 (first received 18 April 2016). [CRS: 4900132000030034]

\section{Partridge 2008 \{published data only\}}

Partridge MR, Caress AL, Brown C, Hennings J, Luker K, Woodcock A, et al. Can lay people deliver asthma selfmanagement education as effectively as primary care based practice nurses?. Thorax 2008;63(9):778-83. [CENTRAL: 647700; CRS: 4900100000022467; PUBMED: 18281394]

Roberts NJ, Boyd K, Briggs A, L Caress A, Partridge MR. Is it costeffective to replace nurses with lay asthma educators in primary care? [Abstract]. Thorax 2010;65(Suppl 4):S10. [CENTRAL: 783533; CRS: 4900100000026310; EMBASE: 70325700]

Roberts NJ, Boyd KA, Briggs AH, Caress AL, Partridge MR. Nurse led versus lay educators support for those with asthma in primary care: a costing study. BMC Pulmonary Medicine 2012;12:52. [CENTRAL: 839481; CRS: 4900100000068575 ; EMBASE: 2012687840; PUBMED: 22958541]

\section{Pulgaron 2010 \{published data only\}}

Pulgaron ER, Salamon KS, Patterson CA, Barakat LP. A problemsolving intervention for children with persistent asthma: a pilot of a randomized trial at a pediatric summer camp. Journal of Asthma 2010;47(9):1031-9. [CENTRAL: 769411; CRS: 4900100000025766; EMBASE: 2010618216; PUBMED: 20858029]

\section{Rice 2015 \{published data only\}}

Rice JL, Matlack KM, Simmons MD, Steinfeld J, Laws MA, Dovey ME, et al. Leap: a randomized-controlled trial of a lay-educator inpatient asthma education program. Patient Education and Counseling 2015;98(12):1585-91. [CENTRAL: 1087159; CRS: 4900132000005351; EMBASE: 2015216121; PUBMED: 26210342]

\section{Srof 2012 \{published data only\}}

Srof BJ, Velsor-Friedrich B, Penckofer S. The effects of coping skills training among teens with asthma. Western Journal of 
Nursing Research 2012;34(8):1043-61. [CENTRAL: 845573; CRS: 4900100000071982; EMBASE: 21511980; PUBMED: 21511980]

Valery 2010 \{published data only\}

Valery PC, Masters IB, Taylor B, Laifoo Y, O'Rourke PK, Chang AB. An education intervention for childhood asthma by Aboriginal and Torres Strait Islander health workers: a randomised controlled trial. Medical Journal of Australia 2010;192(10):574-9. [CENTRAL: 751730; CRS: 4900100000024907; EMBASE: 2010294628; PUBMED: 20477733]

Wallis 2015 \{published data only\} Wallis EM, Salek EC, Steinway C, Stollon N, Trachtenberg SW, Schwartz LA, et al. Transition from pediatric to adult healthcare for youth with complex chronic conditions: a primary care pilot study. Journal of Adolescent Health 2015;56(2 Suppl 1):S125. [CENTRAL: 1066946; CRS: 4900126000025855 ; EMBASE: 71770915]

\section{References to studies awaiting assessment \\ NCT00217776 \{published data only\}}

NCT00217776. School-based approaches to help pre-teens manage asthma. clinicaltrials.gov/show/NCT00217776 (first received 19 September 2005). [CRS: 4900132000030030]

\section{References to ongoing studies}

NCT02293499 \{published data only\}

NCT02293499. Peer led asthma self management for adolescents: PLASMA. clinicaltrials.gov/show/NCT02293499 (first received 24 October 2014). [CRS: 4900132000006187]

\section{Additional references}

\section{Al-Sheyab 2012}

Al-Sheyab N. Power of peer leaders in improving selfmanagement skills among adolescents with asthma. EvidenceBased Nursing 2012;15(2):45-6.

\section{Alanasari 2004}

Alanasari BM. Factor structure of the Arabic version of the selfadministered nicotine dependence scale. Social Behavior and Personality 2004;32(3):255-62.

\section{Bagnall 2015}

Bagnall AM, South J, Hulme C, Woodall J, Vinall-Collier K, Raine $G$, et al. A systematic review of the effectiveness and costeffectiveness of peer education and peer support in prisons. BMC Public Health 2015;15(1):290.

\section{Bender 2006}

Bender BG. Risk taking, depression, adherence, and symptom control in adolescents and young adults with asthma. American Journal of Respiratory and Critical Care Medicine 2006;173(9):953-7.

\section{BTS/SIGN 2016}

British Thoracic Society/Scottish Intercollegiate Guidelines Network. British guideline on the management of asthma. A national clinical guideline. SIGN 153. https://www.britthoracic.org.uk/document-library/clinical-information/asthma/ btssign-asthma-guideline-2016/ (accessed 9 December 2016).

\section{Butz 1994}

Butz AM, Malveaux FJ, Eggleston P, Thompson L, Schneider S, Weeks K, et al. Use of community health workers with inner-city children who have asthma. Clinical Pediatrics 1994;33(3):135-41.

\section{Cain 2006}

Cain JJ, Dickinson WP, Fernald D, Bublitz C, Dickinson LM, West $D$. Family physicians and youth tobacco-free education: outcomes of the Colorado Tar Wars program. Journal of the American Board of Family Medicine 2006;19(6):579-89.

\section{Davis 1994}

Davis LJ Jr, Hurt RD, Offord KP, Lauger GG, Morse RM, Bruce BK. Self-administered Nicotine-Dependence Scale (SANDS): item selection, reliability estimation, and initial validation. Journal of Clinical Psychology 1994;50(6):918-30.

\section{Dennis 2003}

Dennis CL. Peer support within a health care context: a concept analysis. International Journal of Nursing Studies 2003;40(3):321-32.

\section{Department of Health 2001}

Department of Health. The expert patient: a new approach to chronic disease management for the 21st century. http:// webarchive.nationalarchives.gov.uk/20130107105354/http:// www.dh.gov.uk/prod_consum_dh/groups/dh_digitalassets/ @dh/@en/documents/digitalasset/dh_4018578.pdf (accessed 22 February 2016).

\section{GINA 2016}

Global Initiative for Asthma. Global strategy for asthma management and prevention, 2016. http://ginasthma.org/ (accessed 21 March 2016).

\section{Glenton 2011}

Glenton C, Scheel IB, Lewin S, Swingler GH. Can lay health workers increase the uptake of childhood immunisation? Systematic review and typology. Tropical Medicine and International Health 2011;16(9):1044-53.

\section{Global Asthma Network 2014}

Global Asthma Network. The Global Asthma Report 2014. http:// globalasthmareport.org/resources/Global_Asthma_Report_ 2014.pdf (accessed 29 April 2016).

\section{GRADEpro GDT [Computer program]}

GRADE Working Group, McMaster University. GRADEpro GDT. Version accessed 21 March 2016. Hamilton (ON): GRADE Working Group, McMaster University, 2014. 


\section{Haines 2007}

Haines A, Sanders D, Lehmann U, Rowe AK, Lawn JE, Jan S, et al. Achieving child survival goals: potential contribution of community health workers. The Lancet 2007;369(9579):2121-31.

\section{Higgins 2011}

Higgins JPT, Green S, editor(s). Cochrane Handbook for Systematic Reviews of Interventions Version 5.1.0 [updated March 2011]. The Cochrane Collaboration, 2011. handbook.cochrane.org.

\section{Hoey 2008}

Hoey LM, leropoli SC, White VM, Jefford M. Systematic review of peer-support programs for people with cancer. Patient Education and Counseling 2008;70(3):315-37.

\section{Kaunonen 2012}

Kaunonen M, Hannula L, Tarkka MT. A systematic review of peer support interventions for breastfeeding. Journal of Clinical Nursing 2012;21(13-14):1943-54.

\section{Koster 2015}

Koster ES, Philbert D, de Vries TW, van Dijk L, Bouvy ML. "I just forget to take it": asthma self-management needs and preferences in adolescents. The Journal of Asthma 2015;52(8):831-7.

\section{Lawson 2014}

Lawson JA, Janssen I, Bruner MW, Hossain A, Pickett W. Asthma incidence and risk factors in a national longitudinal sample of adolescent Canadians: a prospective cohort study. BMC Pulmonary Medicine 2014;14:51.

\section{Lorig 1986}

Lorig K, Feigenbaum P, Regan C, Ung E, Chastain RL, Holman HR. A comparison of lay-taught and professionaltaught arthritis self-management courses. The Journal of Rhematology 1986;13(4):763-7.

\section{Lorig 2001}

Lorig K, Ritter P, Stewart AL, Sobel DS, Brown BW Jr, Bandura A, et al. Chronic disease self-management program: 2-year health status and health care utilization outcomes. Medical Care 2001;39(11):1217-23.

\section{Moher 2009}

Moher D, Liberati A, Tetzlaff J, Altman D. Preferred reporting items for systematic reviews and meta-analyses: the PRISMA statement. PLoS Medicine 2009;6(7):e1000097. [DOI: 10.1371/ journal.pmed.1000097]

\section{NRAD 2014}

Royal College of Physicians. Why asthma still kills. The National Review of Asthma Deaths (NRAD). https://rcplondon.ac.uk/ projects/national-review-asthma-deaths (accessed 12 February 2016).

\section{Pfeiffer 2010}

Pfeiffer PN, Heisler M, Piette JD, Rogers MA, Valenstein M. Efficacy of peer support interventions for depression: a metaanalysis. General Hospital Psychiatry 2010;33(1):29-36.

\section{Raphael 2013}

Raphael JL, Rueda A, Lion KC, Giordano TP. The role of lay health workers in pediatric chronic disease: a systematic review. Academic Pediatrics 2013;13(5):408-20.

\section{RevMan 2014 [Computer program]}

The Nordic Cochrane Centre, The Cochrane Collaboration. Review Manager (RevMan). Version 5.3. Copenhagen: The Nordic Cochrane Centre, The Cochrane Collaboration, 2014.

\section{Richardson 2006}

Richardson LP, Lozano P, Russo J, McCauley E, Bush T, Katon W. Asthma symptom burden: relationship to asthma severity and depression symptoms. Pediatrics 2006;118(3):1042-51.

\section{Stewart 2013}

Stewart M, Letourneau N, Masuda JR, Anderson S, McGhan S. Online support for children with asthma and allergies. Journal of Family Nursing 2013;19(2):171-97.

\section{WHO 2016}

World Health Organization. Adolescent health. http:// www.who.int/topics/adolescent_health/en/ (accessed 18 August 2016).

\section{Yang 2010}

Yang TO, Sylva K, Lunt I. Parent support, peer support, and peer acceptance in healthy lifestyle for asthma management among early adolescents. Journal for Specialists in Pediatric Nursing 2010;15(4):272-81.

\section{References to other published versions of this review Kew 2016}

Kew KM, Carr R, Crossingham I. Lay-led and peer support interventions for adolescents with asthma. Cochrane Database of Systematic Reviews 2016, Issue 8. [DOI: 10.1002/14651858.CD012331]

* Indicates the major publication for the study

\section{CHARACTERISTICS OF STUDIES}

Characteristics of included studies [ordered by study ID]

Al-sheyab 2012 
Al-sheyab 2012 (Continued)

Setting: 4 high schools in Irbid, Jordan

Participants

Population: 4 schools including 261 included students; 2 schools took part in the Triple A programme (132 students) and 2 schools provided no intervention (129 students)

Age range: approximately 14 to 16 years based on included school years

\section{Baseline characteristics}

Triple A students: $72.7 \%$ had asthma; $63.6 \%$ male; $20.5 \%$ took ICS (23.5\% took a reliever); $25 \%$ student smokers; $72 \%$ family member smokes

Control students: $68.2 \%$ had asthma; $49 \%$ male; $23.3 \%$ took ICS (43.3\% took a reliever); $30 \%$ student smokers; $71.3 \%$ family member smokes

Inclusion criteria: Students from years 8, 9 and 10 were eligible for participation in the study if they had reported wheezing in the past 12 months as identified by the Arabic version of the International Study for Asthma and Allergy Committee (ISAAC) written questionnaire; were physically and cognitively capable of completing the survey; were able to read and converse in both Arabic and English; attended regular school classes; were free of any other major diseases that could affect quality of life measures; and were not concurrently involved in another health-related study

Exclusion criteria: not regularly attending in year 8, 9 or 10; did not experience wheezing in the past 12 months; had other chronic conditions

Intervention: Bilingual Jordanian health workers delivered the content of the peer leader training programme in both English and Arabic. Health workers trained 11 peer leaders from year 11 at each of the intervention schools to deliver the 3 Triple A lessons to year 10 students

Control: standard care - no intervention

Outcomes

The main study outcomes (health-related quality of life (Arabic PAQLQ), self-efficacy to resist smoking (subscale of the Self-Administered Nicotine Dependence Scale) and knowledge of self-management of asthma (Arabic Asthma Knowledge Consumer Questionnaire)) were collected at baseline and at 3 months after the intervention

"Baseline data included demographic characteristics, smoking habits of students and their families, presence of asthma diagnosis by health professionals, and medications using a self-reporting checklist developed by the researchers. Data on asthma symptoms and severity were collected using the Arabic version of the ISAAC written questionnaire (8 questions about symptoms, diagnosis and severity over past 12 months)"

Notes Trial registration: ISRCTN63833842

Funding: The study was supported by Jordan University of Science and Technology, Irbid, Jordan. We also thank the Nursing Council in Jordan for financial support provided throughout the study

\section{Risk of bias}

Bias Authors' judgement Support for judgement

Random sequence genera- Low risk tion (selection bias)

\begin{abstract}
"Four high schools in the Irbid region in northern Jordan were selected using a closed-envelope technique, from a total of 54 public schools that included Year 8 through Year 11, by an individual independent of the research team. Two schools were randomly selected from all the eligible high schools for girls, and the other 2 schools were randomly selected from all the eligible high schools for boys. Schools were stratified according gender to ensure a balanced sample. The selected schools, which were all single gender ( 2 for boys and 2 for girls), agreed to participate in the study"
\end{abstract}


Al-sheyab 2012 (Continued)

"Allocation to groups occurred by using the cluster method of randomization at the school level and the closed-envelope technique stratified for the gender at the school (2 each)"

\begin{tabular}{|c|c|c|}
\hline $\begin{array}{l}\text { Allocation concealment } \\
\text { (selection bias) }\end{array}$ & Low risk & $\begin{array}{l}\text { Most of the information given relates to blinding of sampling rather than to } \\
\text { group allocation }\end{array}$ \\
\hline
\end{tabular}

Blinding of participants High risk Participants and personnel could not be kept blind to group allocation
and personnel (performance bias)

All outcomes

\begin{tabular}{|c|c|c|}
\hline $\begin{array}{l}\text { Blinding of outcome as- } \\
\text { sessment (detection bias) } \\
\text { All outcomes }\end{array}$ & High risk & $\begin{array}{l}\text { All outcomes were self-reported by participants who could not be blinded to } \\
\text { treatment assignment }\end{array}$ \\
\hline
\end{tabular}

Incomplete outcome data Low risk
(attrition bias)

All outcomes

\begin{abstract}
Six students from the intervention group (4.6\%) and $11(8.5 \%)$ from the control group did not complete the trial because they were absent from school on the day of outcome data collection. As school absence due to asthma was one of the outcomes the intervention was intended to impact, it is possible that exclusion of these children from the analysis
\end{abstract}

\begin{tabular}{|c|c|c|}
\hline $\begin{array}{l}\text { Selective reporting (re- } \\
\text { porting bias) }\end{array}$ & Low risk & $\begin{array}{l}\text { Trial was retrospectively (ISRCTN63833842), not prospectively, registered. } \\
\text { Named outcomes are reported in full, but the study was not prospectively reg- } \\
\text { istered. Study authors responded to contact and confirmed that they possess } \\
\text { no additional data relevant to our analyses }\end{array}$ \\
\hline Other bias & Unclear risk & $\begin{array}{l}\text { School selection is described in detail but may have introduced a selection } \\
\text { bias before randomisation }\end{array}$ \\
\hline
\end{tabular}

\section{NCT01161225}

\begin{tabular}{|c|c|}
\hline Methods & $\begin{array}{l}\text { Study design: 9-month single-blind parallel RCT } \\
\text { Setting: an urban city and adjacent suburbs in upstate New York }\end{array}$ \\
\hline Participants & $\begin{array}{l}\text { Population: } 112 \text { adolescents were randomised to an asthma programme led by peers ( } \mathrm{n}=59 \text { ) or by } \\
\text { adults ( } \mathrm{n}=53 \text { ) } \\
\text { Age range: } 13 \text { to } 17 \text { years } \\
\text { Baseline characteristics } \\
71 \% \text { on at least } 1 \text { controller medicine } \\
\text { Peer-led: } 44.1 \% \text { male; mean age } 14.9 \text { years (SD 1.4); } 45.8 \% \text { white } \\
\text { Adult-led: } 41.5 \% \text { male; mean age } 14.5 \text { years (SD 1.3); } 47.2 \% \text { white } \\
\text { Inclusion criteria: (1) age } 13 \text { to } 17 \text { years; ( } 2 \text { ) mild, moderate or severe persistent asthma specified by } \\
\text { NHLBI guidelines; (3) asthma diagnosis } \geq 1 \text { year; (4) no other chronic/emotional health conditions (e.g. } \\
\text { diabetes, cystic fibrosis, major depression); and (5) ability to understand spoken and written English } \\
\text { Exclusion criteria: "Adolescents with learning disabilities based on reports from parents, teachers or } \\
\text { clinicians were excluded, because this could influence the implementation and outcomes of the inter- } \\
\text { vention program" }\end{array}$ \\
\hline
\end{tabular}


teachers/nurses or clinicians and attended 3-week intensive structured training sessions ( 5 hours/wk). Paired peer leaders facilitated learning activities in small groups of 6 to 10 campers, overseen by adults. Younger leaders ( 16 to 17 years of age) led younger groups (13 to 14 years of age); older leaders (18 to 20 years of age) led older groups (15 to 17 years of age). Three 45- to 60-minute sessions based on Power Breathing ${ }^{\mathrm{TM}}$ programme covered basic asthma education, psychosocial issues and asthma self-management skills. Group activities involved discussion, strategic thinking, knowledge-testing games and role playing. At completion of camp, peer leaders conducted monthly phone follow-ups to provide continuous peer support and encouragement using a checklist. Approximately $49 \%$ were successfully reached each month, and average length of the interaction was 2 to 5 minutes for each contact

Control: The control group attended an adult-led day camp that was held at the same camp site on a different day. Two nurse practitioners and a physician offered the campers didactic asthma education. The length of the day camp and the content of the asthma programme were comparable with those of the intervention group

Outcomes The Children's Attitude toward Asthma Scale and the Pediatric Asthma-related Quality of Life Questionnaire were administered at baseline, and immediately and 3, 6 and 9 months post intervention. Spirometry was conducted twice - before the intervention and 9 months after the intervention

Notes Trial registration: NCT01161225

Funding: supported by a grant from the NIH/NINR (R21 NR009837), awarded to Hyekyun Rhee

\section{Risk of bias}

\begin{tabular}{|c|c|c|}
\hline Bias & Authors' judgement & Support for judgement \\
\hline $\begin{array}{l}\text { Random sequence genera- } \\
\text { tion (selection bias) }\end{array}$ & Low risk & $\begin{array}{l}\text { "A total of } 112 \text { adolescents were randomly assigned using a computer generat- } \\
\text { ed random table to either the intervention (peer-led camp) or control (adult- } \\
\text { led camp) group" }\end{array}$ \\
\hline $\begin{array}{l}\text { Allocation concealment } \\
\text { (selection bias) }\end{array}$ & Unclear risk & No details \\
\hline $\begin{array}{l}\text { Blinding of participants } \\
\text { and personnel (perfor- } \\
\text { mance bias) } \\
\text { All outcomes }\end{array}$ & High risk & $\begin{array}{l}\text { Study states, "Participants were blind to their group assignment", and is de- } \\
\text { scribed as "single blind (subject)" on clinicaltrials.gov. Study personnel's } \\
\text { knowledge of group assignment may have introduced bias }\end{array}$ \\
\hline $\begin{array}{l}\text { Blinding of outcome as- } \\
\text { sessment (detection bias) } \\
\text { All outcomes }\end{array}$ & High risk & $\begin{array}{l}\text { Most outcomes were rated by participants, who were unaware of their group } \\
\text { assignment }\end{array}$ \\
\hline $\begin{array}{l}\text { Incomplete outcome data } \\
\text { (attrition bias) } \\
\text { All outcomes }\end{array}$ & Low risk & $\begin{array}{l}\text { A fair quantity of data were missing by the } 9 \text {-month measurement }(27.1 \% \text { and } \\
22.6 \% \text { in intervention and control groups) but the quantity was less at earlier } \\
\text { time points and "analyses were performed using all available data (i.e., intent } \\
\text { to treat), including participants who subsequently dropped out". Risk of bias is } \\
\text { likely to be different depending on the outcome and the time point of interest, } \\
\text { which will be considered in the Grade rating for each outcome individually }\end{array}$ \\
\hline $\begin{array}{l}\text { Selective reporting (re- } \\
\text { porting bias) }\end{array}$ & Low risk & $\begin{array}{l}\text { Study was prospectively registered (NCT01161225), and as planned, all named } \\
\text { outcomes were reported in published papers or on clinicaltrials.gov }\end{array}$ \\
\hline Other bias & Low risk & None noted \\
\hline
\end{tabular}




\section{Methods}

Study design: 10-week open-label parallel RCT

Setting: 3 primary care practices at Rush University Medical Center in Chicago, Illinois

Participants

Population: 68 adolescents were randomised to a peer support and messaging intervention $(n=34)$ or to an attention control group $(n=34)$

Age range: 11 to 16 years

\section{Baseline characteristics}

Peer support:: 50\% male; mean age 13.3 (range 11 to 16 ) years; $85 \%$ had uncontrolled asthma; $26.5 \%$ had 2 or more OCS courses in past 12 months and 57.6 had 1 or more ED visit or hospital admission in past 12 months; $5.9 \%$ current smokers; $8.8 \%$ family member smokes

Attention control: $47.1 \%$ male; mean age 13.6 (range 11 to 16 ) years; $76.5 \%$ had uncontrolled asthma (76.5\%); $29.4 \%$ had 2 or more OCS courses in past 12 months and $44.1 \%$ had 1 or more ED visit or hospital admission in past 12 months; 0 current smokers; $5.9 \%$ family member smokes

Inclusion criteria: 11 to 16 years of age and self-identified as African American or Hispanic, diagnosis of persistent asthma and possessing an active prescription for a daily ICS for asthma. Persistent asthma was defined as asthma symptoms (e.g. cough, wheeze, shortness of breath, chest tightness) more than 2 days per week or night-time awakening more than twice a month; or being on a prescribed daily ICS for asthma. The latter requirement was met when the adolescent within the past 12 months had (1) an outpatient visit to Rush University Medical Center with asthma listed as a diagnosis code for that visit; and (2) a prescription for ICS

Exclusion criteria: caregiver or child unable to speak English, comorbidities that could interfere with study participation, or $\geq 48 \%$ adherence over 2 weeks during the run-in period. Participants with $\geq 48 \%$ adherence were excluded, as the aim of the study was to target children with poor adherence (i.e. who could benefit most from this behavioural intervention)

Interventions

Intervention: peer support and $\mathrm{mp} 3$ messaging. Those in the intervention group received music tracks and attended coping peer group sessions led by social workers during weeks 1 to 4 and 6 to 9 . Session leaders were trained to use a motivational interviewing approach and to follow the study guide. During the session, participants developed and recorded 2 to 4 messages from the discussion to encourage daily use of ICS, to be played at random between music tracks

Control: attention control. All participants received medical supervision, peak flow meters and an iPod during the run-in. Those in the attention control group attended weekly individual sessions with a research assistant who did not promote adherence. They received the same number of iPod messages as those in the active intervention group with content promoting adherence to ICS, also played at random between music tracks, but recorded by an asthma doctor rather than by peers

Outcomes The primary study outcome was ICS adherence (average daily adherence over the previous 14 days) measured with the electronic medication monitor for ICS, measured at baseline and at 5 and 10 weeks. Secondary outcomes were asthma knowledge (ZAP Caregiver Asthma Knowledge Instrument), ICS knowledge, ICS self-efficacy, social support and asthma exacerbations.

Asthma exacerbations included self-reported missed schooldays; oral prednisone bursts; unscheduled urgent visits to the doctor's office; emergency department visits; hospitalisations; intensive care unit admissions; and intubations

Notes Trial registration: NCT01169883

Funding: National Heart Lung and Blood Institute grants K23 HL092292 and R21 HL098812. Support in the form of study drug was provided by a grant from GlaxoSmithKline (FLV114794)

\section{Risk of bias}

Bias Authors' judgement Support for judgement




\section{NCT01169883 (Continued)}

Random sequence genera- Low risk "Blocked group randomization, using a computer-generated allocation schedtion (selection bias) ule"

Allocation concealment $\quad$ Unclear risk $\quad$ No details
(selection bias)

Blinding of participants High risk

and personnel (perfor-

It was not possible to blind participants, although adherence, the only outmance bias)

All outcomes come reported that is of interest in this review, was measured objectively. However, awareness of the intervention group and of monitoring may have affected adherence behaviour beyond the effect intended by the intervention

\begin{tabular}{|c|c|c|}
\hline $\begin{array}{l}\text { Blinding of outcome as- } \\
\text { sessment (detection bias) } \\
\text { All outcomes }\end{array}$ & Low risk & $\begin{array}{l}\text { "Outcomes data were collected at baseline and at } 5 \text { and } 10 \text { weeks post-ran- } \\
\text { domization (during the active treatment phase) by research assistants blinded } \\
\text { to the participants' group assignment" }\end{array}$ \\
\hline
\end{tabular}

Incomplete outcome data Low risk

(attrition bias)

More than $80 \%$ in both arms attended at least 1 follow-up visit (at 5 or 10

All outcomes weeks) and were included in the analysis; reasons for dropping out were similar between groups

Selective reporting (re- High risk
porting bias)
porting bias)

\begin{abstract}
Prospectively registered trial (NCT01169883) and outcomes listed on trial register clearly reported (although medians and IQRs used, so unable to include in meta-analysis). Several outcomes of interest in this review were listed as measured in the methods section of the published report but were not reported in the results (e.g. unscheduled visits, exacerbations)
\end{abstract}

\begin{tabular}{ll}
\hline Other bias $\quad$ Low risk none noted \\
\hline
\end{tabular}

\section{NCT01938976}

\begin{tabular}{ll} 
Methods & Study design: 4-month open-label cluster RCT \\
& Setting: 4 male schools in Irbid, Jordan \\
\hline Participants & $\begin{array}{l}\text { Population: } 4 \text { schools, } 2 \text { randomised to Triple A + smoking pledge, } 2 \text { randomised to Triple A alone. } 53 \\
\text { peer leaders and } 433 \text { students (215 Triple A + smoking pledge, } 218 \text { Triple A alone) included }\end{array}$
\end{tabular}

Age range: 12 to 13 years

\section{Baseline characteristics}

Whole population: all male, $13 \%$ with diagnosed asthma and a further $13 \%$ with reported recent wheezing; $37 \%$ were "ever" smokers

Inclusion criteria: Students from grades 7 and 8 (ages 12 to 13) were eligible to participate if they were capable of completing the survey, were able to read and write in the Arabic language and were free of any major disease that could affect their responses

Exclusion criteria: Students who were concurrently involved in another health-related study were excluded

Interventions

Intervention: The Triple A programme uses a 3-step cascade process plus a smoke-free pledge. Trained health educators trained senior students from grade 10 to be peer leaders $(n=53)$ who deliver 3 sessions to peers in grades 7 and $8(n=433)$. Sessions focused on asthma knowledge, smoking refusal and resistance skills, empowerment and leadership. Resources of the Triple A programme included standardised training manuals for educators and leaders, DVDs about asthma management and smoking and an asthma first aid kit. Motivational strategies included interactive teaching, role-playing, group discussion and a quiz show. Volunteer peers then developed asthma and smoking messages to be presented to the school community as creative performances. Peer leaders also implemented the smoke- 
NCT01938976 (Continued)

free pledge for peers who voluntarily signed the pledge for 4 months. The class, facilitated by peer leaders, monitored adherence on a fortnightly basis for 4 months

Control: The comparison group received the same intervention components as the intervention group, minus the smoke-free pledge

Smoking-related knowledge and perceptions (for all selected students), smoking behaviour (for all
selected students), level of nicotine dependence (for selected students who reported ever cigarette
smoking), screening questionnaire for asthma and recent wheezing; students from this sample who
had an asthma diagnosis or recent wheezing in the past 12 months also completed the questionnaire
on level of asthma control

Notes Trial registration: not reported

Funding: The Deanship of Scientific Research at Jordan University of Science and Technology, Irbid, Jordan (96/2012)

\section{Risk of bias}

\begin{tabular}{|c|c|c|}
\hline Bias & Authors' judgement & Support for judgement \\
\hline $\begin{array}{l}\text { Random sequence genera- } \\
\text { tion (selection bias) }\end{array}$ & Low risk & $\begin{array}{l}\text { "The four selected schools were randomly assigned to either the TAJ or the } \\
\text { TAJ-Plus using an opaque envelope technique to ensure allocation was blind- } \\
\text { ed (Hedges, 2007)." Students were then allocated using "simple random as- } \\
\text { signment allocation using opaque envelope technique". Of all those allocated } \\
\text { (815), a random selection was chosen by "every second student in the alpha- } \\
\text { betical class list" }\end{array}$ \\
\hline
\end{tabular}

\section{Allocation concealment Low risk} (selection bias)
"The four selected schools were randomly assigned to either the TAJ or the TAJ-Plus using an opaque envelope technique to ensure allocation was blinded (Hedges, 2007). The opaque envelope technique is a method used to blind the personnel who were (1) selecting the schools to be approached to join the study and (2) allocating the schools to the experimental and control groups. For the allocation to group, an independent researcher undertook the creation of four allocations (two experimental and two control) and sealed them in opaque envelopes. Once the school principal agreed that the school would participate in the study, an envelope was opened by the independent researcher and the result recorded and the chief investigator advised"

"The random sampling and allocation technique was conducted by a trained, independent researcher"

\begin{tabular}{|c|c|c|}
\hline $\begin{array}{l}\text { Blinding of participants } \\
\text { and personnel (perfor- } \\
\text { mance bias) }\end{array}$ & High risk & $\begin{array}{l}\text { "The cluster design made it possible to blind students to the intervention type } \\
\text { as all participating students within the same school received the same inter- } \\
\text { vention" }\end{array}$ \\
\hline
\end{tabular}

All outcomes

However, it would not be possible to blind personnel to group allocation, and this may have introduced performance bias

\begin{tabular}{lll}
\hline $\begin{array}{l}\text { Blinding of outcome as- } \\
\text { sessment (detection bias) } \\
\text { All outcomes }\end{array}$ & High risk & All questionnaires were self-report and hence were subject to detection bias \\
\hline $\begin{array}{l}\text { Incomplete outcome data } \\
\begin{array}{l}\text { (attrition bias) } \\
\text { All outcomes }\end{array}\end{array}$ & Low risk & $\begin{array}{l}\text { Overall, the trial is at low risk of attrition bias, as } 195 / 215(9.3 \% \text { dropout) stu- } \\
\text { dents in the } 2 \text { intervention schools and } 202 / 218(7.3 \% \text { dropout }) \text { students in the } \\
2 \text { control schools were included in the analyses, but lower numbers were avail- } \\
\text { able depending on the outcome, as "Only students who provided both base- } \\
\text { line and follow-up data were analyzed" }\end{array}$ \\
\hline
\end{tabular}




\section{NCT01938976 (Continued)}

Selective reporting (reporting bias)

Low risk

Named outcomes were reported appropriately but no prospective protocol was available. Study authors responded to contact and confirmed that they possess no additional data relevant to our analyses

Other bias Unclear risk

"The outcome analyses were adjusted for clustering effects as well as any baseline differences between the two groups using the split-plot design"

"All baseline differences between the study groups were adjusted for in the analyses"

\section{Shah 2001}

Methods Study design: 8-month cluster RCT (baseline measures taken in February 1998 and follow-up in October 1998)

Setting: 6 high schools in rural Australia

Participants Population: 272 adolescents were randomised to the Triple A programme $(n=124)$ or to a control group $(n=148)$

Age range: year 7 (12 to 13 years of age) and year 10 (15 to 16 years of age) students

\section{Baseline characteristics}

Triple A: mean age 12.5 for year 7 's, 15.5 for year 10 's; $34.5 \%$ male; $40.7 \%$ taking ICS

Control: mean age 12.5 for year 7 's, 15.5 for year 10 's; $54.3 \%$ male; $32.6 \%$ taking ICS

Inclusion criteria: A video questionnaire from the International Study of Asthma and Allergies in Childhood was administered to all students in years 7 and 10 who were present on the test day (1379 students) at each school in February 1998. Consenting students reporting recent wheeze (272 students) underwent baseline spirometry and completed questionnaires on asthma quality of life and asthma symptoms

Exclusion criteria: not reported

Intervention: The Triple A programme involved a 3-step approach to educating and empowering students with asthma. In step 1, year 11 student volunteers were trained as asthma peer leaders during a 6 -hour workshop conducted by the study team. Students learnt how to educate their peers about asthma and its management using games, videos, worksheets and discussions as teaching tools. In step 2, teams of 3 to 4 peer leaders conducted three 45-minute health lessons for each year 10 class in their school. In step 3, year 10 students developed and presented key messages learnt in lessons to the year 7 students. Presentations by year 10 students included short acts, dramas and songs, with titles such as "don't smoke," "asthma can kill" and "visit your doctor"

Control: Before the study, all schools received first aid kits for asthma and asthma workshops for school staff. All students known to have asthma were issued a record card to be completed by their doctor. In addition, a workshop on adolescent asthma was held for local doctors, and regular reports of the study appeared in local print and electronic media

Outcomes Quality of life, school absenteeism, asthma attacks and lung function

Notes Trial registration: not reported

Funding: The Commonwealth Department of Health and Aged Care and Asthma New South Wales

\section{Risk of bias}


Shah 2001 (Continued)

\begin{tabular}{lll} 
Bias & Authors' judgement & Support for judgement \\
\hline $\begin{array}{l}\text { Random sequence genera- } \\
\text { tion (selection bias) }\end{array}$ & Low risk & $\begin{array}{l}\text { "Concealed random allocation was performed...using a random number gen- } \\
\text { erator" }\end{array}$
\end{tabular}

\begin{tabular}{ll}
\hline $\begin{array}{l}\text { Allocation concealment } \\
\text { (selection bias) }\end{array}$ & Low risk \\
& with the administration of the study), using...the closed envelope technique"
\end{tabular}

\begin{tabular}{ll}
\hline $\begin{array}{l}\text { Blinding of participants } \\
\text { and personnel (perfor- }\end{array}$ & High risk \\
mance description of any blinding procedures. Participants and personnel would \\
have been aware of group assignment
\end{tabular}

mance bias)

All outcomes

Blinding of outcome as- $\quad$ High risk
sessment (detection bias)

No description of any blinding procedures. Participants and personnel would All outcomes have been aware of group assignment, and outcomes were self-reported

\begin{tabular}{|c|c|c|}
\hline $\begin{array}{l}\text { Incomplete outcome data } \\
\text { (attrition bias) } \\
\text { All outcomes }\end{array}$ & High risk & $\begin{array}{l}10 / 148 \text { who had baseline measurements in the intervention group ( } 6.8 \%) \text { and } \\
11 / 124 \text { in the control group }(8.9 \%) \text { had matched data at the end of the trial. It } \\
\text { is not clear at which point randomisation took place. }\end{array}$ \\
\hline & & $\begin{array}{l}\text { "Overall } 1379 \text { (91\%) students completed the asthma screening questionnaire; } \\
325 \text { reported recent wheeze and } 272(83.7 \%) \text { participated in baseline testing } \\
\text { (fig 1). Matched data at both baseline and after the intervention were available } \\
\text { for } 251 \text { students. Missing data occurred owing to misclassification, students } \\
\text { moving schools or being absent on the day of testing, or failure to complete } \\
\text { the questionnaire. These students were similar to the participants in terms of } \\
\text { quality of life and related morbidity measures" }\end{array}$ \\
\hline
\end{tabular}

\begin{tabular}{|c|c|c|}
\hline $\begin{array}{l}\text { Selective reporting (re- } \\
\text { porting bias) }\end{array}$ & High risk & $\begin{array}{l}\text { Exacerbations are not reported for year } 7 \text { pupils in the population, just that } \\
\text { "The intervention had no effect on school absenteeism and asthma attacks in } \\
\text { year } 7 \text { students" Other outcomes are reported, but no associated trial protocol } \\
\text { was provided }\end{array}$ \\
\hline
\end{tabular}

Other bias Low risk None noted

ED: emergency department; ICS: inhaled corticosteroid; ISAAC: International Study for Asthma and Allergy Committee; NHLBI: National Heart, Lung, and Blood Institute; OCS: oral corticosteroid; PAQLQ: Paediatric Asthma Quality of Life Questionnaire; RCT: randomised controlled trial; SD: standard deviation.

\section{Characteristics of excluded studies [ordered by study ID]}

\begin{tabular}{ll}
\hline Study & Reason for exclusion \\
\hline Bruzzese 2008 & Intervention does not match inclusion criteria. Peers and lay leaders not involved \\
\hline Bryant-Stephens 2008 & $\begin{array}{l}\text { Population does not match inclusion criteria. Children between } 2 \text { and } 16 \text { years included, with mean } \\
\text { age of } 6 \text { (i.e. not adolescents) }\end{array}$ \\
\hline Chernoff 2002 & $\begin{array}{l}\text { Population does not match inclusion criteria. Children between } 7 \text { and } 11 \text { years included (i.e. not } \\
\text { adolescents), with a range of chronic illnesses }\end{array}$ \\
\hline Duncan 2013 & $\begin{array}{l}\text { Intervention does not match inclusion criteria. Peers and lay leaders not involved; interventions } \\
\text { were education and parent/child teamwork }\end{array}$ \\
\hline
\end{tabular}




\begin{tabular}{|c|c|}
\hline Study & Reason for exclusion \\
\hline Flores 2009 & $\begin{array}{l}\text { Population does not match inclusion criteria. Intervention aimed at parents of children } 2 \text { to } 18 \\
\text { years of age; mean age was around } 7 \text { (i.e. not adolescents) }\end{array}$ \\
\hline Gibson 1998 & $\begin{array}{l}\text { Design does not match inclusion criteria. "One school received the peer-led Triple A (Adolescent } \\
\text { Asthma Action) program, and the second school served as a comparison school". }\end{array}$ \\
\hline Horner 2008 & $\begin{array}{l}\text { Population does not match inclusion criteria. Children in grades } 2 \text { to } 6 \text { (USA and Canada), with } \\
\text { mean age of } 8.8 \text { (SD 1.2) (i.e. not adolescents) }\end{array}$ \\
\hline JPRN-UMIN000018186 & Design does not match inclusion criteria. Single-arm/uncontrolled \\
\hline Krieger 2009 & $\begin{array}{l}\text { Population does not match inclusion criteria - children were between } 3 \text { and } 13 \text { years of age (mean } \\
\text { age 8) }\end{array}$ \\
\hline Martin 2015 & $\begin{array}{l}\text { Intervention does not match inclusion criteria - home visit community health worker educational } \\
\text { intervention for families }\end{array}$ \\
\hline Mosnaim 2010 & Design does not match inclusion criteria - non-randomly allocated to groups \\
\hline NCT00214669 & Population does not match inclusion criteria - people of all ages ( 3 to 65 ), not just adolescents \\
\hline NCT01725815 & $\begin{array}{l}\text { Population does not match inclusion criteria - adults only }(18+) \text {, and eligible participants could } \\
\text { have any of a range of chronic diseases (hypertension, arthritis, coronary artery disease, hepatitis, } \\
\text { diabetes, asthma, hyperlipidaemia, HIV) }\end{array}$ \\
\hline NCT02747706 & $\begin{array}{l}\text { Population does not match inclusion criteria - children between } 3 \text { and } 12 \text { and intervention aimed at } \\
\text { mentoring parents }\end{array}$ \\
\hline Partridge 2008 & Population does not match inclusion criteria - adults only $(18+)$ \\
\hline Pulgaron 2010 & $\begin{array}{l}\text { Population does not match inclusion criteria. Mean age was } 10.4 \text {, which is just at the lower limit of } \\
\text { adolescence, but study included children as young as } 7 \text { and as old as } 14 \text {. Judged to not be an ado- } \\
\text { lescent population }\end{array}$ \\
\hline Rice 2015 & $\begin{array}{l}\text { Population does not match inclusion criteria. Children } 2 \text { to } 17 \text { years of age, with mean age of } 6.9 \\
\text { (SD 3.9) (i.e. not adolescents) }\end{array}$ \\
\hline Srof 2012 & Intervention does not match inclusion criteria - not peer supported or lay led \\
\hline Valery 2010 & $\begin{array}{l}\text { Population does not match inclusion criteria. Children } 1 \text { to } 17 \text { years of age, with mean age of } 6.9 \\
\text { (SD 4.0) (i.e. not adolescents) }\end{array}$ \\
\hline Wallis 2015 & $\begin{array}{l}\text { Intervention does not match inclusion criteria - aimed at adolescents and young adults } 19 \text { years of } \\
\text { age and older to help transition into adult services }\end{array}$ \\
\hline
\end{tabular}

Characteristics of studies awaiting assessment [ordered by study ID]

\section{NCT00217776}

Methods

Study design: 12-month double-blind parallel randomised controlled trial (RCT)

Setting: 19 public middle schools in Detroit, Michigan
Population: 1292 early adolescents planned - unclear whether recruitment started 
NCT00217776 (Continued)

\section{Age range: 11 to 12 years}

\section{Baseline characteristics}

None. Unclear whether this study was ever completed

Inclusion criteria: 6 th grade students (11 to 12 years of age) enrolled in 19 public middle schools in Detroit, Michigan, who meet the following criteria: attend a participating school; based on National Asthma Education and Prevention Program (NAEPP) guidelines, (1) have a diagnosis of asthma and have active asthma symptoms and/or have received a prescription for asthma medications in the past year, or (2) report the presence of 3 of 5 non-exercise-related asthma symptoms in the past year on 5 or more occasions, or (3) report 2 or more exercise-related asthma symptoms in the past year on 5 or more occasions or (4) have a severity classification of persistent disease (mild, moderate, severe) based on night-time questions

Exclusion criteria: not reported

Interventions

Intervention: "Peer Asthma Action Educational Intervention". Children in this arm will receive BOTH the Open Airways asthma education programme and the Peer Asthma Action education programme. A 6-week asthma educational self-management programme is provided for middle school students plus a Peer Asthma Action Educational Intervention, which is a peer-led training programme for children in multiple grades provided to teach them about asthma and asthma management

Control: "Open Airways Educational Intervention". Children in this arm will receive the Open Airways educational programme, which is an evidence-based asthma educational programme for children, developed by the investigator. A 6-week asthma educational self-management programme is provided for middle school students

Use of healthcare services will be self-reported in telephone interviews with parents at baseline, 12 months and 24 months. Additional primary outcomes listed in the protocol include asthma-related quality of life, disease management behaviour and academic performance. Secondary outcomes include peer support, school attendance, physical activity, use of healthcare services and smoking behaviour

Notes *No results reported or publications listed. Principal investigator deceased (2013). Contacted University of Michigan on $12 / 10 / 2016^{*}$

Trial registration: NCT00217776

Funding: University of Michigan and National Heart, Lung, and Blood Institute (NHLBI)

\section{Characteristics of ongoing studies [ordered by study ID]}

NCT02293499

Trial name or title

Methods

Participants
Peer Led Asthma Self Management for Adolescents: PLASMA (PLASMA)

15-month open-label parallel randomised controlled trial (RCT)

Inclusion criteria: adolescent (camp) participants 12 to 17 years of age; physician-diagnosed asthma that has required use of healthcare services within 12 months; persistent asthma determined by current use of a control medication or $>2$ days/wk of daytime symptoms, $>3$ to 4 times of nighttime awakening, $>2$ days/wk of short-acting beta-agonist (SABA) use or any interference with normal activities due to asthma. Investigators will include those with chronic health conditions, except those with conditions affecting respiratory system, heart disease, pneumonia, etc., and those with moderate to severe cognitive impairment; primary residence located in participating inner cities based on zip codes; and ability to understand spoken and written English 
Eligibility criteria for peer leaders include age 16 to 20 years; nomination from school teachers/nurses or healthcare providers for candidates' exemplary asthma self-management, leadership and emotional intelligence; and fulfilment of eligibility criteria prescribed for adolescent participants

Exclusion criteria: adolescents who are pregnant or incarcerated at enrolment; have learning disabilities based on reports from teachers or clinicians due to possible confounding of results; or have serious health (other than asthma) and emotional preconditions (e.g. severe depression, anxiety disorders, schizophrenia)

Interventions

Intervention: peer-led asthma self-management for adolescents: PLASMA will be implemented in small groups at a camp setting where paired peer leaders will facilitate learning activities. Paired peer leaders will share and coordinate the responsibilities of facilitating group activities. Training content includes the following: Day 1: asthma basics and prevention; Day 2: asthma monitoring and management; Day 3: communication/ psychosocial issue management/leadership training/hands-on practice in simulated peer-led group settings (role-play)

Control: Adult-led asthma self-management will take place within 2 weeks of the peer-led camp to minimise the history effect. Two healthcare professionals will attend peer leader training sessions to become familiar with programme content, then will lead instructional activities. As in PLASMA, adult leaders will base their instruction on the programme manual to ensure comparable programme content. Adult leaders will adopt mainly a didactic format and skill demonstration

Outcomes Primary outcome measures: Pediatric Asthma Quality of Life Questionnaire (PAQLQ)

Secondary outcome measures: Adolescent Asthma Knowledge Questionnaire (AAK); Attitude Toward Asthma Scale (ATA); Asthma Self-Efficacy (ASE); Asthma Outcome Expectation Scale (AOE); Asthma Self-Management Skills (ASM); Asthma Control Test (ACT); Peak Expiratory Flow Rate (PEFR); Perceived Family Support

Other outcome measures: Camp Program Evaluation; Overall Program Evaluation; Peer Leader Rating Scale; Perceived Peer Leader Support Scale

$\begin{array}{ll}\text { Starting date } & \text { November 2014. Final data collection estimated by May 2018. Estimated completion November } \\ 2019\end{array}$
2019

Contact information Hyekyun Rhee, PhD; hyekyun_rhee@urmc.rochester.edu

Notes Currently recruiting participants. Sponsored by University of Rochester. Collaborators listed as Johns Hopkins University and University of Tennessee

\section{DATA AND ANALYSES}

\section{Comparison 1. Peer-led vs control}

\begin{tabular}{lllll}
\hline Outcome or subgroup title & No. of studies & $\begin{array}{l}\text { No. of partici- } \\
\text { pants }\end{array}$ & Statistical method & Effect size \\
\hline $\begin{array}{l}1 \text { Change in asthma-related } \\
\text { quality of life (PAQLQ) }\end{array}$ & 3 & Mean Difference (Random, 95\% Cl) & $0.40[-0.02,0.81]$ \\
\hline $\begin{array}{l}2 \text { Asthma-related quality of } \\
\text { life (MCID) }\end{array}$ & 1 & Odds Ratio (M-H, Random, 95\% CI) & Totals not selected \\
\hline 3 Asthma control & 2 & Mean Difference (IV, Random, 95\% & Totals not selected \\
\hline
\end{tabular}




\begin{tabular}{lllll}
\hline Outcome or subgroup title & No. of studies & $\begin{array}{l}\text { No. of partici- } \\
\text { pants }\end{array}$ & Statistical method & Effect size \\
\hline 4 Smoking & 2 & $\begin{array}{l}\text { Mean Difference (IV, Random, 95\% } \\
\text { Cl) }\end{array}$ & Totals not selected \\
\hline $\begin{array}{l}\text { 4.1 Self-efficacy to stop } \\
\text { smoking }\end{array}$ & 1 & $\begin{array}{l}\text { Mean Difference (IV, Random, 95\% } \\
\text { Cl) }\end{array}$ & $0.0[0.0,0.0]$ \\
\hline $\begin{array}{l}\text { 4.2 Smoking-related knowl- } \\
\text { edge }\end{array}$ & 1 & $\begin{array}{l}\text { Mean Difference (IV, Random, 95\% } \\
\text { Cl) }\end{array}$ & $0.0[0.0,0.0]$ \\
\hline $\begin{array}{l}\text { 4.3 Nicotine dependence } \\
\text { n }\end{array}$ & 1 & $\begin{array}{l}\text { Mean Difference (IV, Random, 95\% } \\
\text { Cl) }\end{array}$ & $0.0[0.0,0.0]$ \\
\hline
\end{tabular}

Analysis 1.1. Comparison 1 Peer-led vs control, Outcome 1 Change in asthma-related quality of life (PAQLQ).

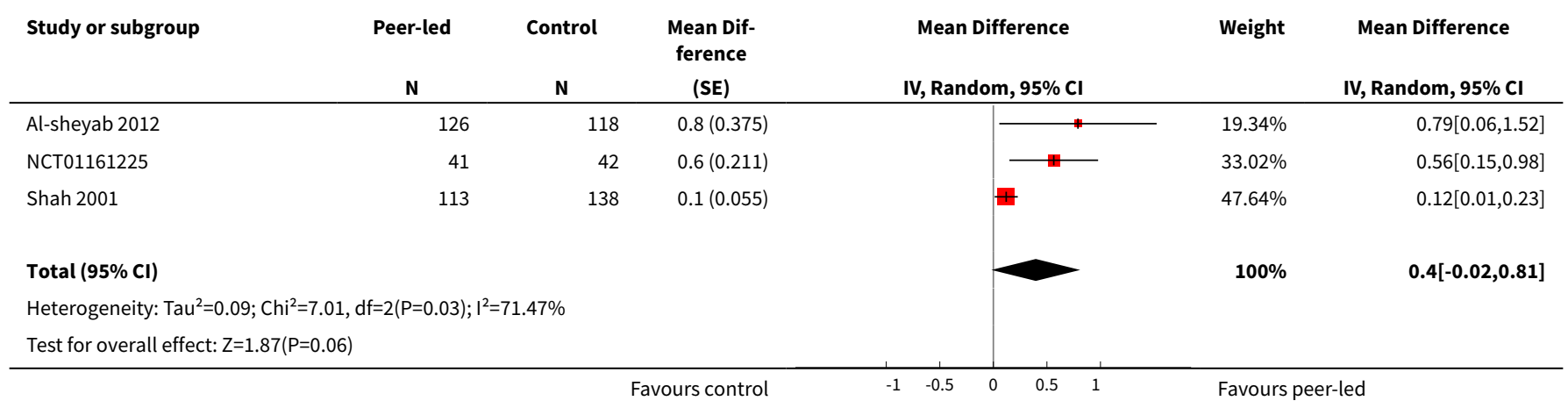

Analysis 1.2. Comparison 1 Peer-led vs control, Outcome 2 Asthma-related quality of life (MCID).

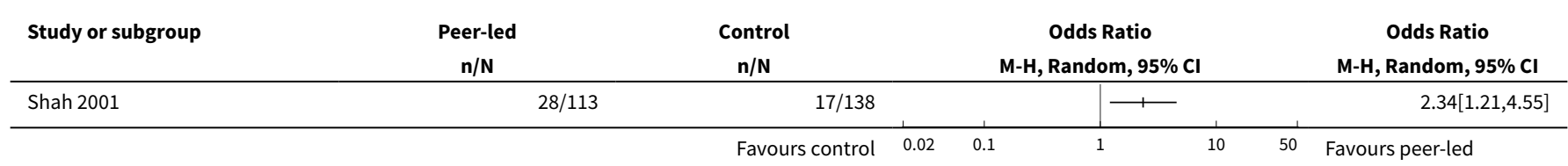

Analysis 1.3. Comparison 1 Peer-led vs control, Outcome 3 Asthma control.

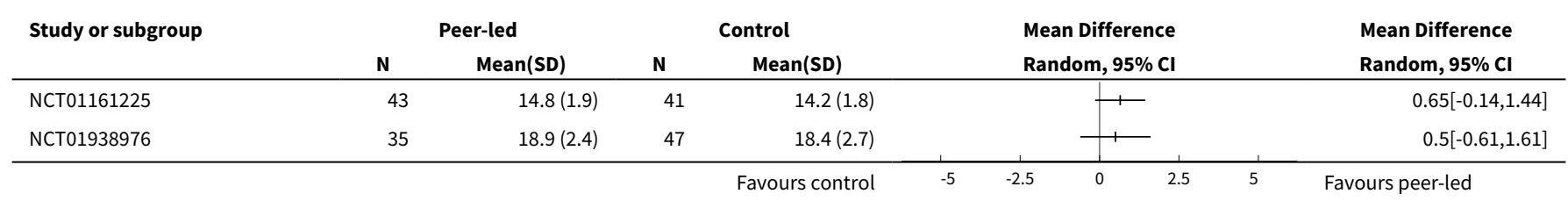


Analysis 1.4. Comparison 1 Peer-led vs control, Outcome 4 Smoking.

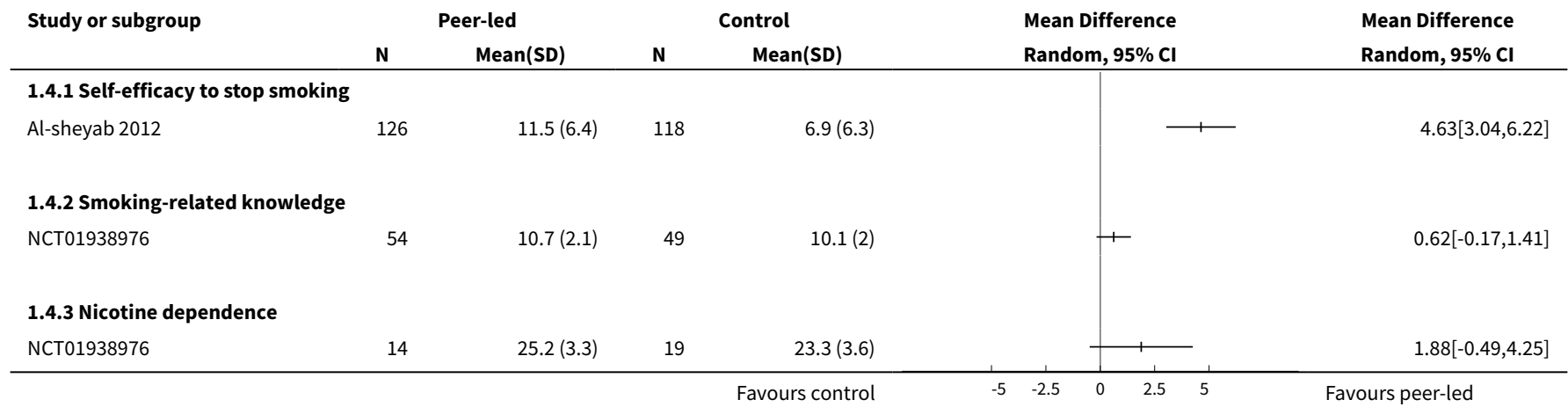




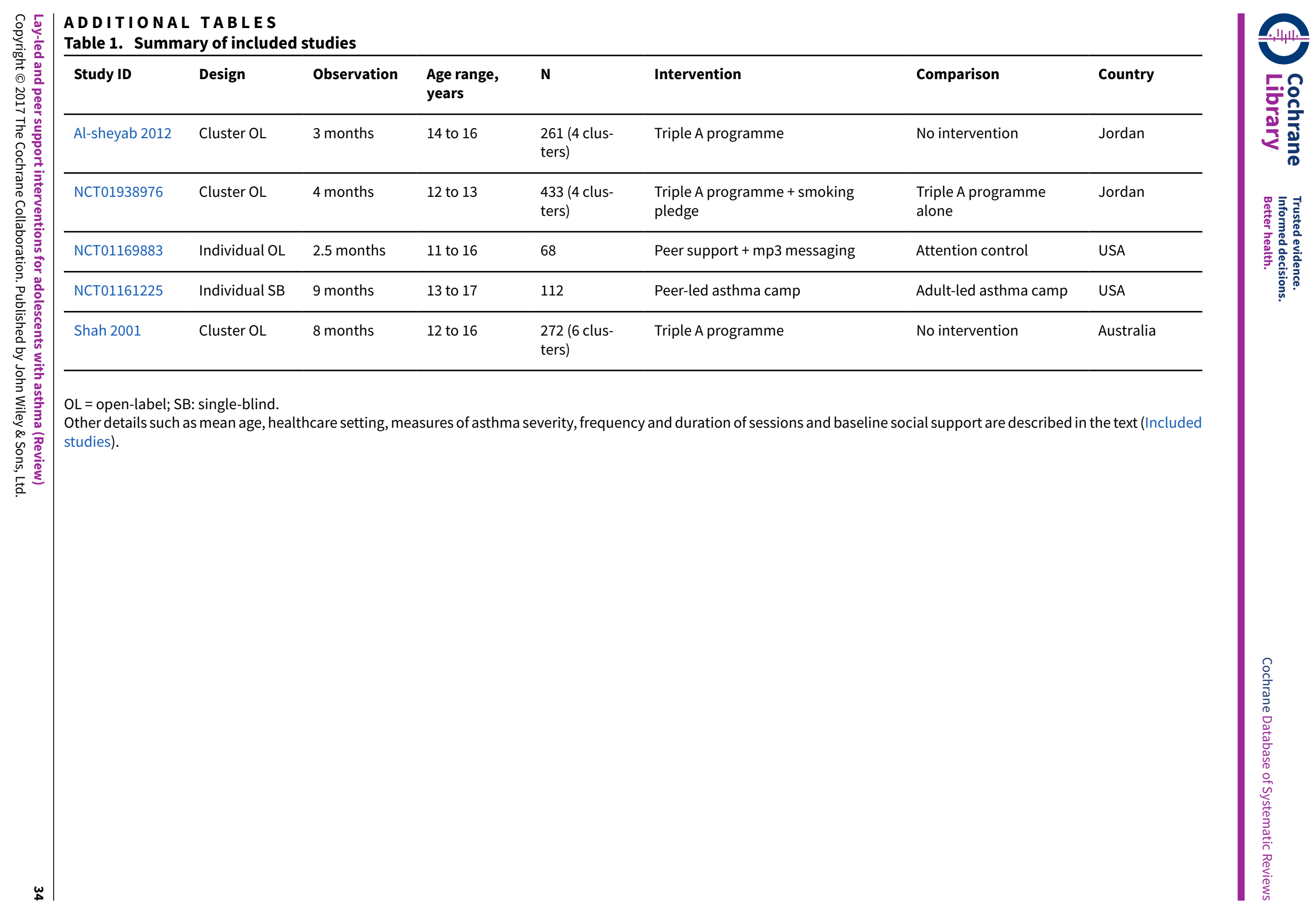




\section{AP PEN DICES}

\section{Appendix 1. Sources and search methods for the Cochrane Airways Group Specialised Register (CAGR)}

Electronic searches: core databases

\begin{tabular}{ll}
\hline Database & Frequency of search \\
\hline MEDLINE (Ovid) & Weekly \\
\hline Embase (Ovid) & Weekly \\
\hline CENTRAL (The Cochrane Library) & Monthly \\
\hline PsyCINFO (Ovid) & Monthly \\
\hline CINAHL (EBSCO) & Monthly \\
\hline AMED (EBSCO) & Monthly \\
\hline
\end{tabular}

Handsearches: core respiratory conference abstracts

\begin{tabular}{ll}
\hline Conference & Years searched \\
\hline American Academy of Allergy, Asthma and Immunology (AAAAI) & 2001 onwards \\
\hline American Thoracic Society (ATS) & 2001 onwards \\
\hline Asia Pacific Society of Respirology (APSR) & 2004 onwards \\
\hline British Thoracic Society Winter Meeting (BTS) & 2000 onwards \\
\hline Chest Meeting & 2003 onwards \\
\hline European Respiratory Society (ERS) & $1992,1994,2000$ onwards \\
\hline International Primary Care Respiratory Group Congress (IPCRG) & 2002 onwards \\
\hline Thoracic Society of Australia and New Zealand (TSANZ) & 1999 onwards \\
\hline
\end{tabular}

\section{MEDLINE search strategy used to identify trials for the CAGR}

\section{Condition search}
1. $\exp$ Asthma/
2. asthma\$.mp.
3. (antiasthma\$ or anti-asthma\$̦).mp.
4. Respiratory Sounds/
5. wheez\$.mp. 
6. Bronchial Spasm/

7. bronchospas\$.mp.

8. (bronch\$ adj3 spasm\$).mp.

9. bronchoconstrict\$.mp.

10. exp Bronchoconstriction/

11. (bronch\$ adj3 constrict\$).mp.

12. Bronchial Hyperreactivity/

13. Respiratory Hypersensitivity/

14. ((bronchial\$ or respiratory or airway\$ or lung\$) adj3 (hypersensitiv\$ or hyperreactiv\$ or allerg\$ or insufficiency)).mp.

15. ((dust or mite\$) adj3 (allerg\$ or hypersensitiv\$)).mp.

16. or/1-15

17. exp Aspergillosis, Allergic Bronchopulmonary/

18. lung diseases, fungal/

19. aspergillosis/

20. 18 and 19

21. (bronchopulmonar\$ adj3 aspergillosis).mp.

22. 17 or 20 or 21

23. 16 or 22

24. Lung Diseases, Obstructive/

25. exp Pulmonary Disease, Chronic Obstructive/

26. emphysema\$.mp.

27. (chronic\$ adj3 bronchiti\$).mp.

28. (obstruct\$ adj3 (pulmonary or lung\$ or airway\$ or airflow\$ or bronch\$ or respirat\$)).mp.

29. COPD.mp.

30. COAD.mp.

31. COBD.mp.

32. AECB.mp.

33. or/24-32

34. exp Bronchiectasis/

35. bronchiect\$.mp.

36. bronchoect\$.mp.

37. kartagener\$.mp.

38. (ciliary adj3 dyskinesia).mp.

39. (bronchial\$ adj3 dilat\$).mp.

40. or/34-39

Lay-led and peer support interventions for adolescents with asthma (Review) 
41. exp Sleep Apnea Syndromes/

42. (sleep\$ adj3 (apnea\$ or apnoea\$)).mp.

43. (hypopnoea\$ or hypopnoea\$).mp.

44. OSA.mp.

45. SHS.mp.

46. OSAHS.mp.

47. or/41-46

48. Lung Diseases, Interstitial/

49. Pulmonary Fibrosis/

50. Sarcoidosis, Pulmonary/

51. (interstitial\$ adj3 (lung\$ or disease\$ or pneumon\$)).mp.

52. ((pulmonary\$ or lung\$ or alveoli\$) adj3 (fibros\$ or fibrot\$)).mp.

53. ((pulmonary\$ or lung\$) adj3 (sarcoid\$ or granulom\$)).mp.

54. or/48-53

55.23 or 33 or 40 or 47 or 54

Filter to identify randomised controlled trials (RCTS)

1. exp "clinical trial [publication type]"/

2. (randomised or randomised).ab,ti.

3. placebo.ab,ti.

4. dt.fs.

5. randomly.ab,ti.

6. trial.ab,ti.

7. groups.ab,ti.

8. or/1-7

9. Animals/

10. Humans/

11. 9 not (9 and 10)

12. 8 not 11

The MEDLINE strategy and RCT filter are adapted to identify trials in other electronic databases.

\section{Appendix 2. Search strategy to identify relevant trials from the CAGR}

\#1 AST:MISC1

\#2 MeSH DESCRIPTOR Asthma Explode All

\#3 asthma*:ti,ab

\#4 \#1 or \#2 or \#3

\#5 MeSH DESCRIPTOR Peer Group 
\#6 peer*:ti,ab,kw

\#7 lay ${ }^{\star}$ NEAR3 (led* or run*):ti,ab,kw

\#8 user* NEAR3 (led* or run*):ti,ab,kw

\#9 lay ${ }^{\star}$ NEAR3 (person* or people* or worker* or person* or advisor ${ }^{\star}$ or consultant ${ }^{\star}$ or leader ${ }^{\star}$ or educator ${ }^{\star}$ or tutor ${ }^{\star}$ or instructor ${ }^{\star}$ or facilitator $\left.{ }^{\star}\right)$

$\# 10$ expert* NEAR3 patient*

\#11 MeSH DESCRIPTOR Voluntary Workers

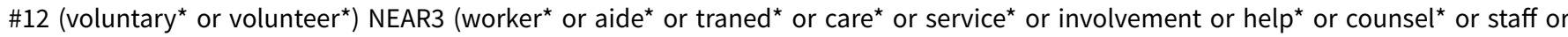
personnel or provider* or group ${ }^{\star}$ )

\#13 MeSH DESCRIPTOR Community Health Workers

\#14 MeSH DESCRIPTOR Community Networks

\#15 MeSH DESCRIPTOR Self-Help Groups

\#16 self* NEXT help*

\#17 MeSH DESCRIPTOR Social Support

\#18 social* NEAR3 support*

\#19 (support ${ }^{\star}$ or career ${ }^{\star}$ or caregiver ${ }^{\star}$ ) NEAR3 (group* or network* or communit*

\#20 mutual $^{\star}$ NEAR3 (aid* or support*)

\#21 MeSH DESCRIPTOR Mentors

\#22 mentor $^{\star}$ or befriend* or buddy or buddies

\#23 \#5 OR \#6 OR \#7 OR \#8 OR \#9 OR \#10 OR \#11 OR \#12 OR \#13 OR \#14 OR \#15 OR \#16 OR \#17 OR \#18 OR \#19 OR \#20 OR \#21 OR \#22

\#24 \#4 and \#23

\#25 MeSH DESCRIPTOR Adolescent

\#26 MeSH DESCRIPTOR Adolescent Health Services

\#27 adolescen*

\#28 youth* $^{*}$

\#29 young* NEAR3 (adult* or person* or people*)

\#30 teen*

\#31 juvenile*

\#32 student*

\#33 \#25 or \#26 or \#27 or \#28 or 29 or \#30 or \#31 or \#32

\#34 \#24 AND \#33

(In search line \#1, MISC1 denotes the field in the record where the reference has been coded for condition, in this case, asthma).

\section{CONTRIBUTIONSOF AUTHORS}

Kayleigh Kew (KK) wrote the Background and Methods sections of this review (based on the standard template), with clinical advice and input from Robin Carr (RC) and lain Crossingham (IC). KK screened all references, extracted data for all studies and assessed risk of bias. Duplicate data extraction and risk of bias were provided by a member of the editorial team (Rebecca Normansell). KK performed the metaanalyses, graded the evidence and led the write-up, with support, feedback and input from RC and IC. 


\section{DECLARATIONS OF INTEREST}

KK: none.

RC: none that are relevant to the interventions considered in this review. RC is a part-time Partnership General Practitioner (GP). He works as the long-term conditions lead for the Oxfordshire Clinical Commissioning Group for respiratory illness and was the Medical Director of the Somerset chronic obstructive pulmonary disease service until October 2014. He received a salary from each of these employers. He organised primary care education for over 20 years and received honoraria from GlaxoSmithKline, Boehringer Ingelheim, AstraZeneca and Chiesi over the past 36 months for presenting lectures to primary care staff. He received travel reimbursement for attending a Cochrane Airways Group meeting in 2014, and again in 2015.

IC: none.

\section{SOURCES OF SUPPORT}

\section{Internal sources}

- Kayleigh Kew, UK.

Supported by St George's, University of London

\section{External sources}

- National Institute for Health Research (NIHR), UK.

Evidence to guide care in adults and children with asthma, 13/89/14

This project was supported by the NIHR, via Cochrane Infrastructure, Cochrane Programme Grant or Cochrane Incentive funding to the Cochrane Airways Group. The views and opinions expressed therein are those of the review authors and do not necessarily reflect those of the Systematic Reviews Programme, the NIHR, the NHS or the Department of Health

\section{DIFFERENCES BETWEEN PROTOCOLAND REVIEW}

We planned that IC and RC would share the duplicate extraction and risk of bias judgements, but this was done by a member of the editorial team owing to work commitments. It was not possible to carry out meta-analyses for all outcomes or to carry out planned subgroup or sensitivity analyses.

\section{N DEX TERMS}

\section{Medical Subject Headings (MeSH)}

*Peer Influence; *Self Care; *Smoking Cessation; *Social Support; Asthma [" ${ }^{*}$ revention \& control]; Disease Progression; Medication Adherence [statistics \& numerical data]; Quality of Life; Randomized Controlled Trials as Topic; Smoking [adverse effects]; Tobacco Use Disorder [epidemiology]

\section{MeSH check words}

Adolescent; Child; Humans 